\title{
APROXIMACIÓN A LOS PARQUES NACIONALES DE LA REGIÓN CAPITAL NACIONAL (QUEBEC, CANADÁ). CONSERVACIÓN Y DESARROLLO ${ }^{1}$
}

\author{
José Manuel Crespo Guerrero \\ Área de Análisis Geográfico Regional \\ Dpto. de Antropología, Geografía e Historia \\ Universidad de Jaén
}

\section{RESUMEN}

Este artículo presenta un panorama general de la política que, durante la primera década del siglo XXI, el gobierno de Québec ha llevado a cabo en los espacios naturales protegidos bajo su competencia. Una vez conseguido el primer objetivo, aumentaremos la escala para acercarnos a los problemas existentes a la hora de casar los conceptos de conservación y desarrollo en los parques nacionales situados en la región administrativa de Capital National. Nos estamos refiriendo a los espacios protegidos de «Jacques Cartier», «Grands Jardins»y «Hautes Gorges de la Rivière Malbaie».

Palabras clave: Quebec, Charlevoix, parques nacionales, gestión, turismo, conservación, desarrollo sostenible, Sépaq.

\section{ABSTRACT}

This article introduces an overview of the general policy on the so-called «natural reserve areas», which was applied during the first decade of the 20th century by the Government of Québec. Once the main purpose has been achieved, we will deal with this topic in depth in order to approach the ultimate difficulties to arise in the event of trying to get some balance between both conservation and development in those national parks which are located within the administrative region of «Capital National». In other words, those preserved areas known as «Jacques Cartier», «Grands Jardins» and «Hautes Gorges de la Rivière Malbaie».

Key words: Québec, Charlevoix, National Parks, management, tourism, conservation, sustainable development and Sépaq (the largest Nature and outdoor network in Québec).

1 La elaboración de este artículo fue financiado por medio de la beca «Comprendre le Canada» otorgada por el Ministerio de Asuntos exteriores y Comercio internacional de Canadá en su convocatoria de 2010. Asimismo, es el resultado de una investigación completada con una estancia en la Universidad de Laval (Quebec) del 15 de julio al 20 de agosto de 2011 . 


\section{Introducción}

La primera década del siglo XXI ha supuesto un verdadero paso adelante en la manera de concebir, tanto cuantitativa como cualitativamente, los espacios naturales protegidos de la provincia canadiense de Quebec. A principios de 2002, el porcentaje de espacios naturales bajo protección alcanzaba el 2,91\% de todo el territorio provincial, es decir, $48.536,6 \mathrm{~km}^{2}$. En la primavera de 2009, según el Ministerio quebequés de Desarrollo sostenible, medio ambiente y Parques (en adelante MDDEP), un total de $136.000 \mathrm{~km}^{2}$ se hallaba bajo alguna figura legal de conservación. Tal superficie representaba el 8,12\% de la extensión total de la provincia, lo que significaba que 1 de cada $12 \mathrm{~km}^{2}$ se encontraba protegido. Este reseñable avance es producto de la puesta en marcha de la Estrategia Quebequés de Espacios Protegidos (SQAP, Stratégie québécoise sur les aires protégées, 2000) mediante el Plan de Acción Estratégica de Espacios Protegidos de Quebec ${ }^{2}$ (PASAP, Plan d'action stratégique sur les aires protégées, 2002); cuyo fin cuantitativo consistió en salvaguardar, bajo criterios culturales, económicos y fundamentalmente, de representatividad de la biodiversidad, al menos, el $8 \%$ del territorio.

En febrero de 2007, se publicó el Registro de Espacios Protegidos de Québec ${ }^{3}$, tal y como obligaba la Ley de Conservación del Patrimonio Natural ${ }^{4}$ aprobada en diciembre de 2002 (LCPN, Loi sur la conservation du patrimoine naturel). Se establecía así un catálogo consensuado con las categorías reconocidas por la Unión Internacional para la Conservación de la Naturaleza (UICN):

«Le ministre tient un registre des différentes aires protégées. $Y$ sont notamment précisés, la superficie, la localisation, le ou les statuts de protection, le ministère, l'organisme gouvernemental ou la personne responsable ainsi que le classement respectif de ces aires en tenant compte des différentes catégories reconnues de l'Union mondiale pour la nature (UICN, 1994) $)^{5}$ »

Sin embargo, este repertorio mostró que en 2007, la provincia de Quebec sólo disponía del 4,79\% $\left(79.893,6 \mathrm{~km}^{2}\right)$ de su territorio protegido, lejos aún del 8\% que se había propuesto para 2005. Los plazos marcados inicialmente en el PASAP no se estaban cumpliendo, pues los intereses en las explotaciones forestales, mineras y energéticas ralentizaban las decisiones gubernamentales en desplegar el PASAP más activamente. Sería el 29 de marzo de 2009 cuando la ministra de Desarrollo Sostenible, Medio Ambiente y Parques, Line Beauchamp, anunciara mediante la publicación del «Retrato de la red de espacios naturales protegidos de Quebec (2002-2009) ${ }^{6} \gg$ no sólo la noticia de haber superado la cifra del 8\%, sino también el firme compromiso de alcanzar el 12\% en 2015 (precisamente, WWF estimaba que

2 http://www.mddep.gouv.qc.ca/biodiversite/aires_protegees/strategie/resultat-plan/aires_protegees.pdf (consultado en julio de 2011).

3 http://www.mddep.gouv.qc.ca/biodiversite/aires_protegees/registre/index.htm

(consultado en julio de 2011).

4 http://www2.publicationsduquebec.gouv.qc.ca/dynamicSearch/telecharge.php?type=2\&file=/C_61_01/ C61_01.htm

(consultado en julio de 2011).

5 Ley sobre la conservación del patrimonio natural, artículo 5. «El ministro tiene un registro de las diferentes áreas protegidas. Donde están detalladamente precisadas, la superficie, la localización, el o los estatutos de protección, el Ministerio, el organismo gubernamental o la persona responsable así como la clasificación respectiva de estas áreas según las diferentes categorías reconocidas de la Unión mundial para la naturaleza (UICN, 1994)».

6 http://www.mddep.gouv.qc.ca/biodiversite/aires_protegees/portrait02-09/fr/intro.pdf

(consultado en julio de 2011) 
en 2004 la media mundial de espacios naturales protegidos se situaba en dicha cantidad). En la primavera de 2011 este porcentaje alcanzaba el 8,32\%, 138.751,76 km² (Gráfico 1).

\section{Gráfico 1}

\section{EVOLUCIÓN PORCENTUAL DE LA SUPERFICIE NATURAL PROTEGIDA EN QUEBEC (CANADÁ) 1987-2011}

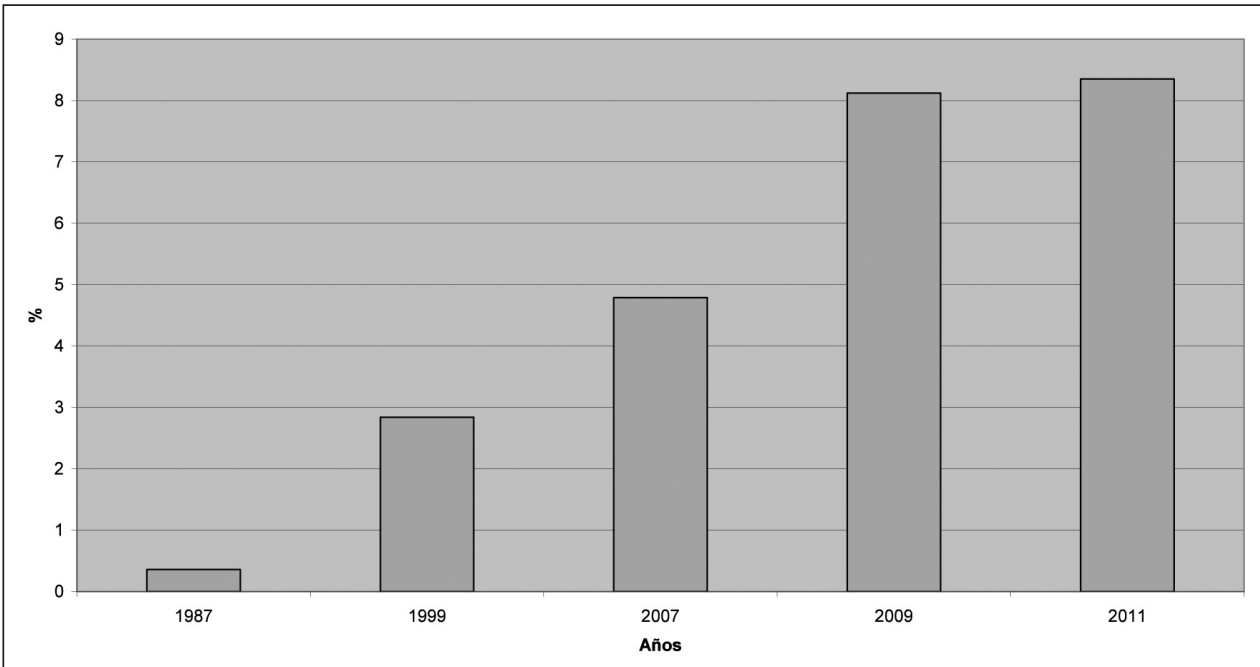

Fuente: Ministerio de Desarrollo Sostenible, Medio Ambiente y Parques (Gobierno de Quebec). Elaboración propia.

\section{Objetivos, estrategias y medios de la política medioambiental de Quebec durante la primera década del siglo XXI}

El 21 de junio de 2000, el Gobierno de Québec ${ }^{7}$ adoptó las orientaciones de la SQAP. En este documento se reconocía un retraso considerable en políticas de conservación de la naturaleza y se establecía una serie de objetivos, de los cuales destacamos los siguientes:

1. Alcanzar la cifra del $8 \%$ del territorio quebequés protegido en 2005 , lo que implicaba aumentar en $85.000 \mathrm{~km}^{2}$ la superficie bajo protección ya existente.

2. Lograr una superficie protegida del orden del $8 \%$ en cada una de las provincias naturales.

3. Obtener un reparto equilibrado y representativo de la biodiversidad de Quebec en las nuevas áreas protegidas.

4. Asegurar al menos un gran espacio protegido por región natural.

5. Aumentar en lo posible la superficie de las pequeñas áreas protegidas.

6. Crear fundamentalmente espacios protegidos de más de $100 \mathrm{~km}^{2}$.

7. Considerar las preocupaciones socioeconómicas de los diversos actores concernidos por la creación de la Red de Espacios Naturales Protegidos.

7 En esta estrategia participaba el Ministerio de Medio Ambiente conjuntamente con los Recursos Naturales y de la Fauna y Parques. 
La creación de nuevos espacios bajo protección en los territorios públicos asociados a numerosos usos y derechos, representaba un desafío para los gestores y los usuarios de estos territorios, y exigía, además, un gran esfuerzo de todos los actores y grupos de interés. Para alcanzar los fines anteriormente presentados, el 15 de mayo de 2002, el Consejo de Ministros de Quebec adoptaba el PASAP conforme a la SQAP. Para su puesta en marcha, el Gobierno quebequés concedió al ministro de Medio Ambiente la coordinación y la preparación de una estrategia común sobre los espacios naturales protegidos, en estrecha coordinación con las carteras de Recursos Naturales y Fauna y Parques. Esta colaboración gubernamental abrió un largo camino de consultas, incluso con otros ministerios y centros oficiales, así como con representantes de la industria, recursos naturales (bosque, minería, energía y turismo), organismos medioambientales y otros sectores concernidos. Desde ese momento, los intercambios permitieron comprender la complejidad de la apuesta y la naturaleza de los impactos de una estrategia de tal dimensión.

Para asegurar un marco jurídico en materia de protección de la biodiversidad, Quebec promulgó, en diciembre de 2002, la Ley de Conservación del Patrimonio Natural ${ }^{8}$. A continuación citamos alguno de los avances más significativos de este nuevo marco legal:

a) Se crean nuevas figuras de protección de la naturaleza con el objeto de dar respuesta a los desafíos actuales de conservación: reservas acuáticas, reservas de biodiversidad y paisajes humanizados.

b) Se confieren poderes adicionales al ministro de Medio Ambiente, que permiten cesar toda actividad de explotación, paralizar obras o exigir la restauración de un espacio degradado.

c) Queda obligada la elaboración y publicación de un registro oficial de espacios naturales protegidos, siempre conforme a las orientaciones de la UICN.

d) Se prevé un régimen de penalización que pueda alcanzar los 200.000 \$ canadienses (\$ CAN) para quienes infrinjan los reglamentos de las áreas protegidas inscritas en el registro oficial.

e) Permite asegurar una protección provisional de los territorios que potencialmente pudieran integrar el registro de espacios naturales protegidos.

f) Define nuevos mecanismos, modalidades y normas de protección e, igualmente, presenta los medios de constitución y gestión de espacios, cuya acción comprendía desde la conservación íntegra de los territorios hasta modalidades de protección más centrados en la gestión sostenible e integrada de los recursos biológicos.

Por lo tanto, la nueva política medioambiental contó con una estrategia general (SQAP), un plan de acción (PASAP) y un marco legislativo de apoyo (LCPN). No obstante, los objetivos de la SQAP no podían obviar el contexto general del territorio de Quebec. Los nuevos espacios naturales protegidos debían tener presente la superficie global del territorio quebequés ${ }^{9}$, las regiones administrativas ${ }^{10}$ (tabla 1 y mapa 1 ), las unidades de ordenación forestal $^{11}$ (UAF, unités d'aménagement forestier), la zona de aplicación del Plan norte ${ }^{12}$

8 http://www.mddep.gouv.qc.ca/infuseur/communique.asp?no=305 (consultado en julio de 2011).

http://www2.publicationsduquebec.gouv.qc.ca/dynamicSearch/telecharge.php?type=2\&file=/C_61_01/C61_01. htm (consultado en julio de 2011).

9 Según las autoridades quebequenses, éste alcanza $1.667 .926 \mathrm{~km}^{2}$.

10 http://www.mamrot.gouv.qc.ca/organisation-municipale/cartotheque/cartes-regionales/

(consultado en julio de 2011).

11 La unidad de ordenación forestal es una unidad territorial de base para la gestión de los recursos forestales y la elaboración de las estrategias a seguir en la organización forestal de los trabajos silvícolas con vistas a determinar las posibilidades forestales. http://plans-thematiques.mrnf.gouv.qc.ca/unite.asp

12 Es un plan que tiene como fin el desarrollo de la industria quebequés minera, forestal e hidroeléctrica. El Plan norte abarca una superficie de 1,1 millones de $\mathrm{km}^{2}$, es decir, el 71,59\% del territorio de Quebec. Las 
(Plan nord) y las categorías de gestión de espacios protegidos de la $\mathrm{UICN}^{13}$, en la cual se inspiraba el Repertorio de Espacios Naturales de Quebec.

Tabla 1

EXTENSIÓN DE LAS REGIONES ADMINISTRATIVAS DE QUEBEC (CANADÁ)

\begin{tabular}{|l|r|}
\hline \multicolumn{1}{|c|}{ Regiones administrativas de la provincia de Quebec (Canadá) } & Superficie (km²) \\
\hline (1) Bas-Saint-Laurent & 22.405 \\
\hline (2) Saguenay-Lac-Saint-Jean & 104.035 \\
\hline (3) Capitale-Nationale & 19.286 \\
\hline (4) Mauricie & 39.748 \\
\hline (5) Estrie & 10.187 \\
\hline (6) Montreal & 504 \\
\hline (7) Outaouais & 32.841 \\
\hline (8) Abitibi-Témiscamingue & 64.700 \\
\hline (9) Côte-Nord & 300.281 \\
\hline (10) Nord-du-Québec & 718.729 \\
\hline (11) Gaspésie-Îles-de-la-Madeleine & 20.937 \\
\hline (12) Chaudière-Appalaches & 15.128 \\
\hline (13) Laval & 245 \\
\hline (14) Lanaudière & 13.528 \\
\hline (15) Laurentides & 21.563 \\
\hline (16) Montérégie & 11.114 \\
\hline (17) Centre-du-Québec & 6.926 \\
\hline
\end{tabular}

Fuente: Ministerio de Asuntos Municipales, Regiones y Ocupación del Territorio (Gobierno de Quebec). Elaboración propia.

Se entendía igualmente, que para que una red de espacios naturales protegidos fuera eficaz en la conservación de la biodiversidad, debía asegurar la salvaguarda tanto de los elementos poco frecuentes, únicos y excepcionales, como aquellos representativos y comunes que definían la biodiversidad del territorio ${ }^{14}$, manteniendo una muestra de cada tipo de ecosistema del territorio a una escala conveniente de percepción.

Para que el principio de representatividad de la biodiversidad se pudiera llevar a cabo, inicialmente se utilizó el Cuadro Ecológico de Referencia ${ }^{15}$ (CER, Cadre écologique de référence). A grandes rasgos, el CER es una herramienta cartográfica y de clasificación del territorio, tanto terrestre como acuática. Cartografía las entidades naturales según distintos

comunidades indígenas afectadas por este plan son las Innus, Cris e Inuit. Dicho plan ha sido muy criticado por diversos sectores de estas poblaciones al considerar que es un proyecto a corto plazo y que sólo tiene como fin esquilmar los recursos naturales de los territorios a los que afecta (Costa Norte y Norte del Quebec). Desde el punto de vista de protección de la naturaleza, los espacios naturales protegidos han pasado de ocupar del 2,40\% del territorio en 2002, al 9,40\% en 2009. Sin embargo, en la zona situada al sur del espacio de aplicación del Plan norte, el porcentaje sólo ha pasado del 4,10\% al 4,97\% en el mismo período.

http://plannord.gouv.qc.ca/english/ (consultado en julio de 2011).

13 http://data.iucn.org/dbtw-wpd/edocs/PAPS-016-Es.pdf (consultado en julio de 2011).

14 Noss, R.F. \& ScotT, J.M. (1995): Endangered ecosystems of the United States: A preliminary assessment of loss and degradation. Biological Report 28. Washington, DC: National Biological Service.

15 http://www.mddep.gouv.qc.ca/biodiversite/cadre-ecologique/cer-bref.htm

(consultado en julio de 2011). 


\section{Mapa 1 \\ REGIONES ADMINISTRATIVAS DE LA PROVINCIA DE QUEBEC (CANADÁ)}

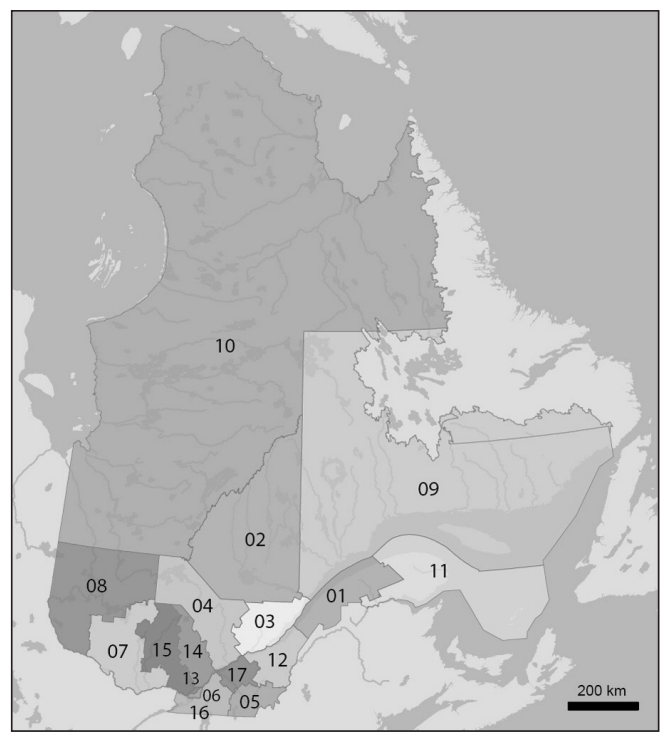

Fuente: Departamento de Geografía de la Universidad de Laval. Reproducción autorizada.

niveles (en el medio terrestre, hay ocho niveles de percepción ${ }^{16}$, que abarcan desde la escala 1: 5.000 .000 para las provincias naturales, hasta la 1: 5.000 para estudios topográficos más detallados; y seis niveles de percepción para el medio acuático, la escala más pequeña es la 1: 250.000 para la denominada hidro-eco-región y la más grande la 1: 5.000 para estudios de flujos más concretos). Así, se conseguía distinguir los ecosistemas según los elementos permanentes del territorio, tales como la geología, el relieve, los tipos de suelo; los cuales determinan la naturaleza de los grandes ecosistemas. De hecho, en un contexto climático dado, la base física de un territorio permite establecer las formas de vida (vegetal y animal) que le son potencialmente asociados.

El CER divide el territorio quebequés en 13 provincias naturales, primera escala de análisis territorial. Estas provincias naturales sirven de base para el estudio de la representatividad de la red de espacios naturales protegidos (tabla 2 y mapa 2). A partir de este primer nivel, la escala de información va aumentando. Supongamos que todas las formas de vida que son asociadas a una unidad estuvieran incluidas. Esta aproximación, denominada «filtro bruto» permite teóricamente cubrir la mayor parte de la biodiversidad de Quebec. Dicho análisis de la representatividad de variables permanentes del territorio, se completa con otras hasta llegar al «filtro final». Este último define los elementos poco comunes, como la presencia de especies amenazadas o vulnerables de flora y fauna, o elementos físicos particulares. La complementariedad de estas dos aproximaciones, «filtro bruto»y «filtro final», optimiza el grado de representatividad ecológica de los territorios elegidos. Las antiguas masas forestales fueron igualmente integradas como procesos de selección de los espacios protegidos en las provincias naturales sujetas a la explotación forestal, con el fin de que pudieran contribuir a resolver este desafío ecológico.

16 http://www.qc.ec.gc.ca/faune/biodiv/fr/abiotique/terr_cadre.html (consultado en septiembre de 2011) 
Tabla 2

EXTENSIÓN DE LAS PROVINCIAS NATURALES DE QUEBEC

\begin{tabular}{|c|c|}
\hline Provincias naturales de Quebec (Canadá) & Superficie $\left(\mathbf{K m}^{2}\right)$ \\
\hline (A) Los Apalaches & 69.000 \\
\hline (B) Tierras bajas del río San Lorenzo & 29.000 \\
\hline (C) Laurentides meridionales & 163.000 \\
\hline (D) Laurentides centrales & 205.000 \\
\hline (E) Meseta de la baja costa norte & 130.000 \\
\hline (F) Tierras bajas del Abitibi y bahía James & 99.000 \\
\hline (G) Tierras altas de Mistassini & 93.000 \\
\hline (H) Colinas bajas del Gran río & 173.000 \\
\hline (I) Meseta central del Norte del Quebec & 159.000 \\
\hline (J) Península de Ungava & 252.000 \\
\hline (K) Cuenca de la bahía de Ungava & 103.000 \\
\hline (L) Montes Torngat & 42.000 \\
\hline (X) Estuario del golfo del río San Lorenzo ${ }^{17}$ & 152.000 \\
\hline
\end{tabular}

Fuente: Ministerio de Desarrollo sostenible, medio ambiente y parques de Quebec ${ }^{18}$. Elaboración propia.

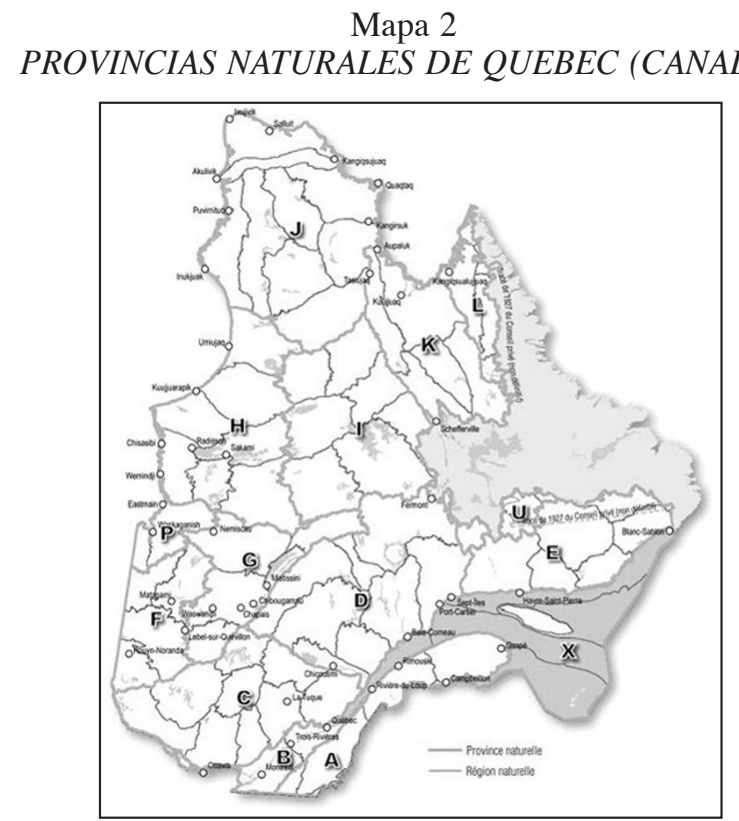

Fuente: MDDEP [http://www.mddep.gouv.qc.ca/biodiversite/cadre-ecologique/index.htm]

17 Se define como «X» al ser un espacio acuático y no terrestre como las otras provincias naturales.

18 http://www.mddep.gouv.qc.ca/biodiversite/aires_protegees/provinces/ (consultado en julio de 2011). 
La contribución de los espacios protegidos a la preservación de los ecosistemas y especies se mide por medio de la calidad de las aproximaciones de caracterización ecológica de ecosistemas y especies. Los análisis de representatividad son realizados a partir de la identificación de los tipos de medio físico (terrestre y acuático), los modelos de cobertura (vegetación potencial y zonas de vegetación), dominios climáticos, territorios forestales (productivos e improductivos), antigüedad de las masas forestales y de las especies amenazadas o vulnerables. Estos estudios permiten comprender los beneficios realizados en materia de representatividad de la biodiversidad de la red y determinar, en su caso, las carencias aún existentes.

El PASAP concluyó el 29 de marzo de 2009, tras el anuncio de haber alcanzado e incluso superado el 8\% del territorio de Quebec bajo protección medioambiental. El 20 de abril de 2011 fueron adoptadas las nuevas orientaciones medioambientales ${ }^{19}$ horizonte 2015 , con el fin de alcanzar la cifra del $12 \%$, para así entrar en la media mundial de espacios naturales protegidos ${ }^{20}$. Ello supondría superar los $200.000 \mathrm{~km}^{2}$ preservadas medioambientalmente, es decir, salvaguardar 1 de cada $8 \mathrm{Km}^{2}$.

\subsection{Clasificación final de los espacios naturales protegidos}

El MDDEP consagró importantes esfuerzos en seleccionar y delimitar los lugares a proteger, según la representatividad de los ecosistemas que estaban siendo estudiados. La elección de un espacio protegido y su extensión final jugaban un papel fundamental para fijar el grado de protección y por ende su figura legal. Según la LCPN, los espacios naturales protegidos de Quebec debían clasificarse, considerando seis categorías de gestión propuestos por la UICN (tabla 3 ).

Tabla 3

CATEGORÍAS DE GESTIÓN DE LAS ÁREA PROTEGIDAS SEGÚN LA UICN Y SU CORRESPONDIENTE EN QUÉBEC

\begin{tabular}{|l|l|l|}
\hline Categoría & \multicolumn{1}{|c|}{ UICN } & \multicolumn{1}{c|}{ Figura de protección en Quebec } \\
\hline Ia & Reserva estricta & Reserva ecológica \\
\hline Ib & Área de vida salvaje & Ninguna \\
\hline II & Parque nacional & Parque nacional de Quebec \\
\hline III & Monumento natural & $\begin{array}{l}\text { Reserva de la biodiversidad; reserva acuática; } \\
\text { refugio de aves }\end{array}$ \\
\hline IV & Área de gestión de hábitat/especies & Espacio de confinamiento del ciervo de Virginia \\
\hline V & Paisajes terrestres/marinos protegidos & Ninguna \\
\hline VI & Área protegida de recursos gestionados & $\begin{array}{l}\text { Zona de concentración de aves acuáticas; } \\
\text { Refugio de fauna; Reserva nacional de fauna }\end{array}$ \\
\hline
\end{tabular}

Fuente: Ministerio de Desarrollo sostenible, medio ambiente y parques de Quebec $^{21}$ e $\mathrm{UICN}^{22}$. Elaboración propia.

19 http://www.mddep.gouv.qc.ca/biodiversite/aires_protegees/orientations-strateg2011-15.pdf (consultado en julio de 2011).

20 En octubre de 2010, Quebec participó en el Protocolo de Nagoya en la que 165 países ratificaron el Convenio sobre la Diversidad Biológica, comprometiéndose a aumentar los espacios protegidos de los países firmantes al 17\% en 2020. http://www.cbd.int/abs/ (consultado en julio de 2011).

21 http://www.mddep.gouv.qc.ca/biodiversite/aires_protegees/registre/index.htm

(consultado en julio de 2011).

22 http://data.iucn.org/dbtw-wpd/edocs/PAPS-016-Es.pdf (consultado en julio de 2011). 
De entre todas las figuras de protección vigentes en Quebec (tabla 4), la de mayor calado territorial es, sin lugar a dudas, la de Reserva de biodiversidad protegida (categoría III de gestión de áreas protegidas de la UICN). Los 77 espacios bajo esta figura ocupan una extensión de $58.635,25 \mathrm{~km}^{2}$, lo que equivale al 42,26\% de toda la superficie salvaguardada de la provincia de Quebec. Tras ella le siguen las 7 reservas de parque nacional de Quebec (categoría II de gestión de áreas protegidas de la UICN), distribuidas en $30.001,41 \mathrm{~km}^{2}$, es decir el 21,62\% de todos los espacios naturales protegidos. En tercera posición aparece la figura de Reserva de territorio para ser espacio protegido (categoría II de gestión de áreas protegidas de la UICN); los 4 territorios que contienen esta denominación cubren un total de $18.489,80 \mathrm{~km}^{2}$, el 13,26\% de las áreas protegidas. No muy lejos de este dato, se halla la cuarta figura por representatividad territorial, la de Parque nacional bajo administración quebequés, (categoría II de gestión de áreas protegidas de la UICN). Son 24 los parques nacionales que se extienden en una superficie de $10.567,44 \mathrm{~km}^{2}$, prácticamente el $7,62 \%$ del espacio protegido. Estas cuatro figuras de conservación de la naturaleza equivalen a casi el 85\% de todo el espacio protegido de Quebec, de los cuales, el 42,74\% pertenece a la categoría II y el restante $42,26 \%$ corresponde a la categoría III de protección de la UICN.

Un dato nada desdeñable es que esta Red de Espacios Protegidos se extiende fundamentalmente en tierras de dominio público (según datos oficiales, el 92\% del territorio total protegido ${ }^{23}$ ).

Tabla 4

DESIGNACIÓN EXTENSIÓN Y REPRESENTATIVIDAD DE LOS ESPACIOS NATURALES PROTEGIDOS DE QUEBEC (2011)

\begin{tabular}{|c|c|c|c|}
\hline Designación de la figura de protección & Número & $\begin{array}{l}\text { Superficie } \\
\text { en }^{k^{2}}{ }^{2}\end{array}$ & $\begin{array}{l}\text { Porcentaje } \\
\quad \%\end{array}$ \\
\hline 1.a Ecosistema forestal excepcional - Antigua masa forestal & 117 & 255,17 & 0,18 \\
\hline 1.b Ecosistema forestal excepcional - Masa forestal singular & 45 & 35,62 & 0,03 \\
\hline 1.c Ecosistema forestal excepcional - Masa forestal refugio & 14 & 13,47 & 0,01 \\
\hline 2 Hábitat de una especie vegetal amenazada o vulnerable & 50 & 49,34 & 0,04 \\
\hline 3.a Hábitat faunístico - Área de concentración de aves acuáticas & 734 & $3.547,34$ & 2,56 \\
\hline $\begin{array}{l}\text { 3.b Hábitat faunístico - Área de confinamiento del ciervo de } \\
\text { Virginia }\end{array}$ & 114 & $2.319,74$ & 1,67 \\
\hline 3.c Hábitat faunístico - Colonia de aves en acantilados & 5 & 0,89 & 0,00 \\
\hline 3.d Hábitat faunístico - Colonia de aves en isla o península & 109 & 0,39 & 0,00 \\
\hline 3.e Hábitat faunístico - Hábitat de la rata almizclada & 134 & 35,84 & 0,03 \\
\hline $\begin{array}{l}\text { 3.f Hábitat faunístico - Hábitat de una especie faunística } \\
\text { amenazada o vulnerable }\end{array}$ & 2 & 2,30 & 0,00 \\
\hline 3.g Hábitat faunístico - de la ardea (banda de protección 0-200 m) & 81 & 16,70 & 0,00 \\
\hline 3.h Hábitat faunístico - Cenagal & 3 & 0,01 & 0,00 \\
\hline 4. Medio marino protegido & 1 & $1.245,30$ & 0,90 \\
\hline 5. Medio natural de conservación voluntaria & 194 & 147,02 & 0,11 \\
\hline 6. Parque de la Comisión de Capital Nacional (Canadá) & 1 & 361,31 & 0,26 \\
\hline
\end{tabular}

23 http://www.mddep.gouv.qc.ca/biodiversite/aires_protegees/contexte/partie3.htm (consultado en julio de 2011). 


\begin{tabular}{|l|r|r|r|}
\hline 7. Parque nacional de Quebec & 24 & $10.567,44$ & 7,62 \\
\hline 8. Parque nacional y reserva de parque nacional de Canadá & 3 & 897,33 & 0,65 \\
\hline 9. Refugio biológico & 483 & 870,81 & 0,63 \\
\hline 10. Refugio de aves migratorias & 27 & 501,56 & 0,36 \\
\hline 11. Refugio faunístico & 11 & 21,14 & 0,01 \\
\hline 12. Reserva acuática & 1 & 1,49 & 0,00 \\
\hline 13. Reserva acuática proyectada & 8 & $6.699,94$ & 4,83 \\
\hline 14. Reserva de biodiversidad & 5 & $2.286,16$ & 1,65 \\
\hline 15. Reserva de biodiversidad proyectada & 77 & $58.635,25$ & 42,26 \\
\hline 16. Reserva de territorio para ser espacio protegido & 4 & $18.489,80$ & 13,26 \\
\hline 17. Reserva de parque nacional de Quebec & 7 & $30.001,41$ & 21,62 \\
\hline 18. Reserva ecológica & 71 & 951,04 & 0,68 \\
\hline 19. Reserva ecológica proyectada & 5 & 638,28 & 0,46 \\
\hline 20. Reserva nacional de fauna & 8 & 61,60 & 0,04 \\
\hline 21. Reserva natural reconocida & 76 & 98,07 & 0,07 \\
\hline 22. Paisaje Humanizado & 0 & 0 & 0 \\
\hline 23. Paisaje humanizado proyectado & 0 & 0 & 0 \\
\hline Total & $\mathbf{2 . 4 1 4}$ & $138.751,76$ & $\mathbf{1 0 0}$ \\
\hline
\end{tabular}

Fuente: Ministerio de Desarrollo Sostenible, Medio Ambiente y Parques (Gobierno de Quebec). Elaboración propia ${ }^{24}$.

La creación de nuevos espacios naturales protegidos en esta nueva era, ha requerido un importante ejercicio de armonización, principalmente entre los intereses económicos ligados a la explotación de los recursos naturales y los intereses de conservación del territorio. Inicialmente, el MDDEP invitó a todos los ciudadanos, organismos y comunidades a presentar proposiciones de creación de espacios protegidos en tierras de propiedad pública. Esta invitación se realizó durante la gira informativa que acompañó a los trabajos de designación de territorios de interés para la constitución de nuevas áreas protegidas. Los principales titulares de derechos de explotación de los terrenos seleccionados fueron consultados por medio del Ministerio de Recursos Naturales y Fauna (MRNF, ministère des Ressources naturelles et de la Faune). Mientras, la Oficina de Audiencias Públicas de Medio Ambiente (BAPE, Bureau des audiences publiques sur l'environnement) realizó más de una decena de consultas sobre los territorios en reserva con objetivos de protección.

Se podría afirmar que Quebec asiste a una nueva generación de espacios naturales fundamentados en los criterios de la UICN, cimentados en el consenso social y el reconocimiento de su papel en el bienestar y la calidad de vida de las personas.

24 http://www.mddep.gouv.qc.ca/biodiversite/aires_protegees/registre/index.htm (consultado en julio de 2011).

http://www.mddep.gouv.qc.ca/biodiversite/aires_protegees/registre/Fig_1_Aires_prot.pdf (consultado en julio de 2011).

http://www.mddep.gouv.qc.ca/biodiversite/aires_protegees/registre/reg-design/index.htm (consultado en julio de 2011). 


\subsection{La red de parques nacionales de Quebec (Parcs Québec): marco jurídico y configuración}

La Ley de Parques de $1977^{25}$ dotó a la provincia de Quebec de los poderes necesarios para establecer parques de conservación y de recreación; en ellos, quedaba prohibida la explotación de sus recursos, con excepción de la pesca. Mont-Orford fue el primer territorio protegido bajo esta figura legislativa (1979), al que le siguieron, dos años más tarde, los de Mont-Tremblant, Gaspésie, Jacques-Cartier y Grands-Jardins. Esta ley propició de modo decisivo la creación de la actual Red de Parques Nacionales de Quebec.

Dos momentos claves en la historia reciente de los parques quebequenses se fecharon en 1999 y 2001. En el primer año, se funda la Sociedad de Establecimientos al Aire Libre de Quebec (Sépaq, Société des établissement de plein-air du Québec), creada con el objeto, en general, de asegurar una adecuada gestión de las actividades y servicios de lugares e infraestructuras públicas con vocación recreativa y turística. En el segundo año, se modificó la Ley de Parques para dar respuesta a los nuevos criterios internacionales dictados por la UICN. Así, se sustituyeron las figuras de parque de conservación y recreación por el de parque nacional. Quebec se convertía en la primera provincia de Canadá en adoptar una ley que respondía totalmente a criterios internacionales. A partir de ese momento, se entendió como parque nacional a un territorio representativo de una región natural, con vocación de preservar el patrimonio natural y accesible a todos los ciudadanos, para que éstos descubrieran, comprendieran y disfrutaran sus riquezas naturales. Bajo este espíritu nació la red «Parques Quebec». La modificada Ley de Parques determina el concepto de parque nacional, su administración ${ }^{26}$ y la adopción de reglamentos ${ }^{27}$, para la protección del territorio.

«1.b) Un parc national dont l'objectif prioritaire est d'assurer la conservation et la protection permanente de territoires représentatifs des régions naturelles $d u$ Québec ou de sites naturels à caractère exceptionnel, notamment en raison de leur diversité biologique, tout en les rendant accessibles au public pour des fins d'éducation et de récréation extensive.»

La Sépaq gestiona, además de la isla de Anticosti, tres grandes redes: la formada por un grupo de veintidós parques nacionales de Quebec, la integrada por dieciséis reservas faunísticas y la constituida por nueve centros turísticos de carácter público, en donde se incluyen el Aquarium y el Jardín zoológico de Quebec. Igualmente, cogestiona junto con la Agencia Parques Canadá (Parcs Canada $^{28}$ ), el parque marino Saguenay-Saint-Laurent.

La Red de Parques Nacionales de Quebec, denominada Parcs Québec está gestionada por dos sociedades. Por un lado, la Sépaq que administra los veintidós parques nacionales quebequenses situados por debajo del paralelo 50; y por otro, Parc du Nunavik ${ }^{29}$ que se

25 http://www2.publicationsduquebec.gouv.qc.ca/dynamicSearch/telecharge.php?type=2\&file=//P_9/P9.htm

26 Cada parque se administra por un comité de gestión compuesto por un director y responsables de los servicios de conservación y educación, clientela y servicios comunitarios.

27 Regulan diversos aspectos como los relativos a la zonificación, condiciones de acceso, estancia, práctica de actividades, así como los derechos y los deberes de los empleados.

http://www2.publicationsduquebec.gouv.qc.ca/dynamicSearch/telecharge.php?type=2\&file=\%2F\%2FP_9\%2 FP9R25.htm (consultado en julio de 2011).

28 http://www.pc.gc.ca/progs/np-pn/index_f.asp (consultado en julio de 2011).

29 Dependiente de la administración regional Kativik (ARK) inserta en la región administrativa de Norte del Quebec. Esta administración se creó en 1978 en virtud de la Convención de Bahía James y Norte quebequés. La Administración regional de Kativik representa a todos los habitantes de la región, enuits y no enuits. Está financiada por el gobierno de Quebec (50\%) y el de Canadá (25\%). El restante 25\% es la aportación local. 
encarga de los dos ubicados por encima del nombrado paralelo y situados en la provincia administrativa de Norte del Quebec. También hay que subrayar que hay una red federal de parques nacionales de Canadá gestionada por Parcs Canada ${ }^{30}$. En ésta se halla el parque nacional de La Mauricie $\left(536 \mathrm{~km}^{2}\right)$ que se sitúa en la provincia de Quebec y que, por consiguiente, ni integra Parques Quebec ni está gestionada por la Sépaq.

La Sépaq es una empresa rentable para el Estado, aunque no los resultados económicos procedentes de los parques nacionales, cuyas pérdidas se equilibran con los ingresos procedentes de las actividades que se ofertan en las reservas faunísticas (por ejemplo, la caza) y los centros turísticos.

La figura de parque nacional no debe ser identificada con la de «reserva de parque nacional». Los territorios bajo esta denominación, aunque son espacios naturales protegidos, no tienen la misma protección jurídica que los parques. Dichos espacios se encuentran situados exclusivamente en Nunavik, prefiriéndose utilizar la figura de «reserva de biodiversidad» para el resto de regiones de Québec.

Así pues, 24 parques nacionales (tabla 5) son los que integran la red Parques Quebec. Se extienden en una superficie de $10.567,44 \mathrm{~km}^{2}$ lo que equivale al $0,63 \%$ de toda la superficie de Québec ${ }^{31}$, o el 7,62\% de todos los espacios naturales protegidos de la provincia. Estos datos, a los que podríamos catalogar como modestos, son aún menos atractivos si tenemos en cuenta que el parque más extenso, el de Kuururjuaq, representa el 42,2\% de toda la red, con sus más de $4.460 \mathrm{~km}^{2}$. Si a esta importante cifra, le sumamos las de los dos siguientes parques en extensión, el de Mont-Tremblant $\left(1.510,01 \mathrm{~km}^{2}\right)$ y Pingualuit $\left(1.130,90 \mathrm{~km}^{2}\right)$, indica que sólo estos tres abarcan el 67,2\% de la extensión de toda la red, de los cuales dos, el de Kuururjuaq y Pingualuit se localizan en Nunavik (región administrativa de Norte del Quebec). En el lado opuesto, están los parques nacionales de Miguasha $\left(0,62 \mathrm{~km}^{2}\right)$, îleBonaventure-et-du-Rocher-Percé $\left(5,80 \mathrm{~km}^{2}\right)$ y Mont-Saint-Bruno $\left(5,90 \mathrm{~km}^{2}\right)$. La extensión media de un parque nacional quebequés, excluyendo los tres parques de mayor superficie y los otros tres más pequeños, es de 161,69 km² (la media real arroja la cifra de 359,26 Km², casi el doble que la media mejorada).

Tabla 5

LISTADO DE LA RED PARQUES NACIONALES DE QUEBEC (2011)

\begin{tabular}{|l|r|r|l|l|}
\hline \multicolumn{1}{|c|}{ Parque nacional } & $\begin{array}{c}\text { Superficie } \\
\text { en } \mathbf{~ k m}^{2}\end{array}$ & \multicolumn{1}{c|}{$\begin{array}{c}\text { Año de } \\
\text { constitución }\end{array}$} & $\begin{array}{c}\text { Provincia } \\
\text { natural }\end{array}$ & $\begin{array}{c}\text { Región } \\
\text { administrativa }\end{array}$ \\
\hline Aiguebelle & 268,30 & 1985 & (F) & $(8)$ \\
\hline Anticosti & 57,18 & 2001 & $(\mathrm{X})$ & $(9)$ \\
\hline Bic & 33,20 & 1984 & (A) & $(1)$ \\
\hline Fjord-du-Saguenay & 319,30 & 1983 & (D) & $(2) ;(3) ;(9)$ \\
\hline Frontenac & 155,30 & 1987 & (A) & $(5) ;(12)$ \\
\hline Gaspésie & 802,00 & 1981 & (A) & $(1) ;(11)$ \\
\hline Grands-Jardins & 310,00 & 1981 & (D) & $(3)$ \\
\hline Hautes-Gorges-de-la-Rivière-Malbaie & 224,70 & 2000 & (D) & $(3)$ \\
\hline Île-Bonaventure-et-du-Rocher-Percé & 5,80 & 1985 & (A) & $(11)$ \\
\hline Îles-de-Boucherville & 8,14 & 1984 & (B) & $(16)$ \\
\hline
\end{tabular}

30 Agencia federal responsable de los parques nacionales de Canadá, los lugares históricos nacionales y las áreas marinas nacionales de conservación.

31 Hemos tomado como referencia de la extensión de Quebec, los datos ofrecidos por el Ministerio de Desarrollo Sostenible, Medio Ambiente y Parques: $1.667 .926 \mathrm{~km}^{2}$. 


\begin{tabular}{|l|r|r|l|l|}
\hline \multicolumn{1}{|c|}{ Parque nacional } & $\begin{array}{c}\text { Superficie } \\
\text { en km }^{2}\end{array}$ & $\begin{array}{c}\text { Año de } \\
\text { constitución }\end{array}$ & $\begin{array}{c}\text { Provincia } \\
\text { natural }\end{array}$ & $\begin{array}{c}\text { Región } \\
\text { administrativa }\end{array}$ \\
\hline Jacques-Cartier & 670,60 & 1981 & (D) & $(3)$ \\
\hline Kuururjuaq & $4.460,80$ & 2009 & (L) & $(10)$ \\
\hline Lac-Témiscouata & 176,50 & 2009 & (A) & $(1)$ \\
\hline Miguasha & 0,62 & 1985 & (A) & $(11)$ \\
\hline Mont-Mégantic & 54,86 & 1994 & (A) & $(5)$ \\
\hline Mont-Orford & 59,43 & 1979 & (A) & $(5)$ \\
\hline Mont-Saint-Bruno & 5,90 & 1985 & (B) & $(16)$ \\
\hline Mont-Tremblant & $1.510,01$ & 1981 & (C) & $(15)$ \\
\hline Monts-Valin & 154,00 & 1996 & (D) & $(2)$ \\
\hline Oka & 23,70 & 1990 & (B) & $(15)$ \\
\hline Plaisance & 28,10 & 2002 & (C) & $(7)$ \\
\hline Pingualuit & $1.133,90$ & 2004 & (J) & $(10)$ \\
\hline Pointe-Taillon & 92,20 & 1985 & (D) & $(2)$ \\
\hline Yamaska & 12,90 & 1983 & (B) & $(16)$ \\
\hline Total & $10.567,44$ & & & \\
\hline
\end{tabular}

Fuente: Ministerio de Desarrollo Sostenible, Medio Ambiente y Parques (Gobierno de Quebec). Elaboración propia ${ }^{32}$.

En consecuencia, los parques nacionales quebequenses presentan una extensión muy variable, abarcando desde los $0,62 \mathrm{~km}^{2}$ de Miguasha hasta los más de $4.460 \mathrm{~km}^{2}$ de Kuururjuaq. Si comparamos la extensión media mejorada de dichos parques, 161,69 km², con la misma media de los parques naturales andaluces ${ }^{33}, 582,51 \mathrm{~km}^{2}$, llegamos a la conclusión de que en general estas zonas protegidas de Quebec son de pequeña extensión ${ }^{34}$; información relevante, si consideramos la teoría de la biogeografía de las islas ${ }^{35}$ que sostiene que cuanto más pequeña y aislada sea una isla, menos especies albergará.

Desde la modificación de la Ley de Parques en 2001, cinco nuevos espacios protegidos bajo la figura de parque nacional se han sumado a Parques Quebec (Anticosti, Plaisance, Lac-Témiscouata, Kuururjuaq y Pingualuit). Está en estudio la creación del parque nacional más extenso de todo Quebec, el de Tursujuq, en la región Norte, el cual abarcará 26.910 Km² y será gestionado por Parques Nunavik ${ }^{36}$.

Obviamente, desde la puesta en marcha de la SQAP se ha producido un aumento significativo tanto del número, como de la superficie de los parques nacionales bajo administración quebequenses (Gráfico 2 y 3). Durante la década de 2000 se duplicó el número de parques nacionales en relación a los constituidos en todos los años noventa del siglo pasado. Si bien el período en el que más parques nacionales se crearon fueron los ochenta, la superficie que se protegió resultó menor que la de los años 2000; en concreto, se

32 http://www.mddep.gouv.qc.ca/biodiversite/aires_protegees/registre/reg-design/index.htm

(consultado en julio de 2011).

33 No se han contabilizado los parques menores de $800 \mathrm{~km}^{2}$ (de la Breña y marismas del Barbate, Despeñaperros y Montes de Málaga) ni lo mayores de $2.000 \mathrm{~km}^{2}$ (Sierras de Cazorla, Segura y Las Villas).

34 La extensión media real de los parques naturales andaluces es de $582,51 \mathrm{~km}^{2}$ frente a los $359,3 \mathrm{~km}^{2} \mathrm{de}$ los parques nacionales quebequenses.

35 McArthur, R.H.; Wilson E.O. (1968): «An equilibrium theory of insular zoogeography», Evolution, número 17 , pp. 373-387.

36 Para hacernos una idea de la extensión de este parque, digamos que la provincia de Badajoz, la de mayor superficie de España, abarca $21.766 \mathrm{~km}^{2}$. 
protegieron $1.886,91 \mathrm{~km}^{2}$ más en la primera década del siglo XXI que en los años 1980 . En el decenio 2000-2010 se establecieron dos de los tres parques más extensos de la red, los de Pingualuit $\left(1.130,90 \mathrm{~km}^{2}\right)$ y Kuururjuaq $\left(4.460 \mathrm{~km}^{2}\right.$ ) ambos, como apuntamos, en la provincia del Norte del Quebec.

Gráfico 2

EVOLUCIÓN DEL NÚMERO DE PARQUES NACIONALES

QUEBEQUENSES (1970-2010)

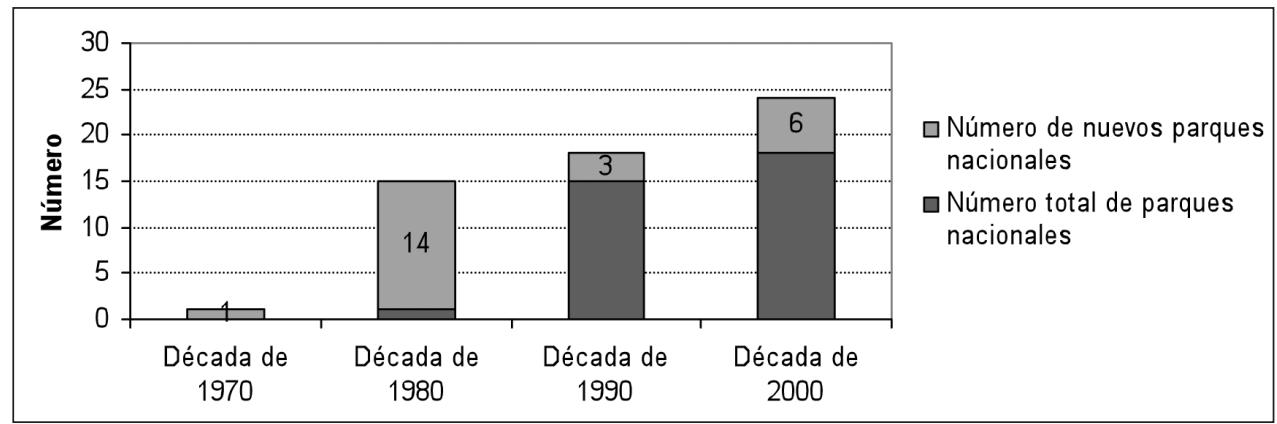

Fuente: Ministerio de Desarrollo Sostenible, Medio Ambiente y Parques (Gobierno de Quebec). Elaboración propia.

Gráfico 3

EVOLUCIÓN DE LA EXTENSIÓN DE PARQUES NACIONALES

QUEBEQUENSES (1970-2010)

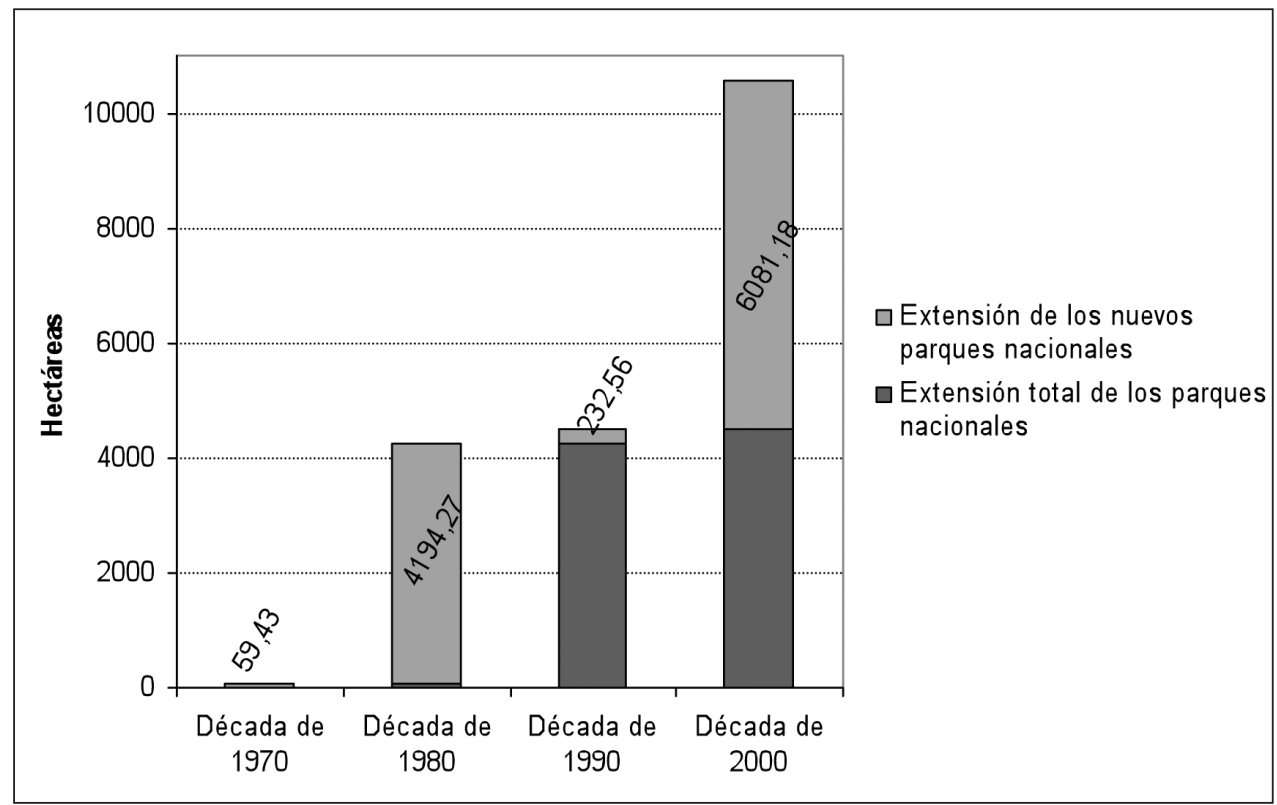

Fuente: Ministerio de Desarrollo Sostenible, Medio Ambiente y Parques (Gobierno de Quebec). Elaboración propia. 
Para terminar, cabría puntualizar que si bien la base legal de parque nacional implica el asegurar la conservación y protección permanente de territorios representativos de las provincias naturales de Quebec, lo cierto es que de las trece provincias que integran el territorio quebequés, en cinco no se ha instituido ningún parque nacional. Nos referimos a las provincias naturales de «Meseta de la baja costa Norte» (E), «Tierras altas de Mistassini» $(\mathrm{G})$, «Colinas bajas del Gran río» (H), «Meseta central del Norte del Quebec» (I) y «Cuenca de la bahía de Ungava» (K). Todas estas regiones naturales representan el 39,46\% de toda la provincia de Québec, unos $658.000 \mathrm{~km}^{2}$. A esta crítica, se le suma la realizada por otros estudios científicos los cuales aseveran que frecuentemente estos parques se han creado sin un conocimiento exhaustivo de la diversidad y de la dinámica de sus ecosistemas, por lo que consideran que aún hoy, los espacios protegidos de Québec están lejos de cubrir toda la riqueza en especies y hábitats de la provincia, particularmente en la zona $\operatorname{sur}^{37}$.

Mejor representadas están las regiones administrativas, pues de las 17 existentes, en sólo cinco de ellas no hay parques nacionales, nos referimos a las muy pobladas, pero pequeñas en extensión, regiones de Montreal (6) y Laval (13), y las tres regiones limítrofes y bañadas por el río San Lorenzo de Mauricie (4), Lanaudière (14) y Centre-du-Québec (17); éstas constituyen el 3,6\% de toda la provincia. Dicho dato sería aún menor si consideramos el parque nacional de la Mauricie, gestionado por Parques Canadá, y sito en la región administrativa homónima.

\subsection{Conservación y desarrollo en los parques nacionales de Quebec: el papel de la SÉPAQ}

Desde la aprobación de la Ley de 1977, Quebec ha creado parques cuyos objetivos prioritarios han sido la conservación y la protección permanente de los territorios representativos de las regiones naturales o sitios naturales excepcionales, así como su accesibilidad con fines recreativos y educativos. En materia de conservación, la ley prohíbe toda forma de prospección y explotación de los recursos con fines forestales, mineros o energéticos. Se practica la pesca y en general, cualquier actividad recreativa considerada de bajo impacto.

La gestión de los parques nacionales está fuertemente marcada por la propiedad, en su totalidad pública, y la inexistencia de núcleos de población en su interior. De tal manera que la dimensión del concepto desarrollo es diferente a la de espacios protegidos como los andaluces, en donde la propiedad privada y las actividades humanas, fruto de la vida del Hombre en el territorio, son variables a sumar en la difícil ecuación entre conservación y desarrollo. Una vez realizadas las consiguientes valoraciones, debemos subrayar que la gestión de los parques de Quebec tuvo un importante punto de inflexión tras la publicación, en noviembre de 1996, del informe del Comité de Reactivación de los Parques Quebequenses. Dicho informe constató importantes problemas de gestión relativos a la conservación y accesibilidad (papel recreacional y educativo); traducidos en ausencia y deficiencias de infraestructuras básicas, débil presencia de los parques en la sociedad, inadecuada financiación, falta de una perspectiva común entre los agentes locales, descoordinación, etc. Este documento sirvió de justificación para crear la Sépaq, a la que se le encomendó los siguientes objetivos:

1. Dirigir los parques a un nivel de calidad en materia de conservación y desarrollo comparable al de las grandes redes internacionales de parques nacionales.

2. Optimizar la contribución financiera de las actividades comerciales.

37 Sarakinos, H; Nicholls, A.O.; Tubert, A.; Aggarwal, A.; Margules, C.R.; Sarkar, (2001): «Area prioritization for biodiversity conservation in Quebec on de basis of species distributions: a preliminary analysis», Biodiversity and conservation, número 10, pp. 1419-1472. 
3. Posicionar Parques Quebec a nivel nacional, federal e internacional, como una red de parques nacionales de calidad, con el fin de aumentar las visitas y por ende, su presencia en la sociedad.

4. Asegurar una gestión rigurosa de los parques con el objeto de contribuir al desarrollo de las regiones administrativas de Quebec.

Constituir la Sépaq no fue fácil. Con anterioridad, una treintena de organismos regionales gestionaban las actividades comerciales y velaban por la conservación de los parques. Los diferentes intereses de los organismos regionales hacían a todas luces imposible desarrollar una estrategia común en el conjunto de los parques, tanto en la administración de los productos recreativos, como en la conservación. Motivo suficiente para que el Gobierno de Quebec decidiera recuperar la gestión. Fueron necesarios dos años de conversaciones para llegar a una serie de acuerdos, entre los que destaca la transferencia del personal de los antiguos organismos regionales a la recién creada sociedad. La Sépaq se convertía en la responsable de la oferta de actividades y servicios de cada parque, y en el órgano de aplicación de las políticas de conservación.

Desde entonces, el gobierno de Quebec no ha cesado de aumentar las partidas presupuestarias de la Sépaq. Según Raymond Desjardins, director general de Parques Quebec, se ha pasado de un presupuesto que rondaba los 25 millones de \$CAN en 2000/2001, a más de 46 millones en el período 2007/2008 y se han invertido paralelamente en ese tiempo más de 100 millones de dólares para la mejora y creación de infraestructuras de acogida y aventura. La Sépaq ha registrado un aumento del 5\% de sus ingresos en 2009/2010 hasta alcanzar la cifra de 118.959.000 $\$ \mathrm{CAN}^{38}$ y entorno a los 3,6 millones de visitantes, de los cuales el $90 \%$ son quebequenses y el resto, de otras provincias canadienses y europeos ${ }^{39}$. La difusión de la imagen de los parques nacionales, se ha visto apoyada por una importante campaña de marketing y diversificación de su oferta turística (yurtas, iglús, tiendas de campaña Huttopia...) Según las últimas encuestas de satisfacción, el 96\% de los visitantes canadienses y estadounidenses considera que los parques nacionales de la provincia de Quebec pueden compararse favorablemente con aquellos de la red de Canadá o los EE.UU., los más reputados de Norteamérica. Este esfuerzo tuvo su primer reconocimiento en noviembre de 2010, cuando la Asociación de la Industria Turística de Canadá (TIAC) otorgó a la Sépaq el prestigioso premio nacional a la excelencia turística.

En enero de 2011 se aprobaron las nuevas tarifas de la red de Parques Quebec ${ }^{40}$. Éstas suscitaron un importante debate entre los amantes quebequenses de la naturaleza, ya que registraron aumentos de entorno al $57 \%$ en los precios de los productos ofertados. Entrar a un parque nacional pasaba de costar 3,5 \$CAN a 5,5 \$CAN, cantidad que irá aumentando progresivamente hasta los $8,5 \$ C A N$ para el $2016(+146 \%)^{41}$. Según la revista especializada Espaces $^{42}$, en un contexto en que la gente joven acampa cada vez menos, el aumento de precios no parece ser una buena manera de contribuir a uno de los objetivos de los parques nacionales: la educación. Sin embargo, otras voces, afirman que acceder a la naturaleza incluso por 8,5 \$CAN sigue siendo más económico que ir a ver una película en una sala de cine. Resaltemos que ese precio es sólo por el acceso al parque, al que habría que in-

38 http://www.carnetsdaventures.ca/2011/01/la-sepaq-augmentera-ses-tarifs-en-2011/

39 Marcotte, P; Bordeau, L. (2009): «Les parcs nationaux du Québec : une expérience touristique, l'accessibilité et les défis», FrancVert, le webzine environnemental, volumen 6, número 2.

40 Tarifas de acceso a los parques nacionales desde el 16 de abril de 2011 hasta el 31 de marzo de 2011: http://www.sepaq.com/pq/tarification-parcs-nationaux.dot (consultado en julio de 2011)

41 La tarifa de entrada está en vigor desde 2001. Su puesta en marcha suscitó una gran polémica que poco a poco ha ido desapareciendo.

42 http://www.espaces.ca/ (consultado en julio de 2011) 
cluir otras cantidades derivadas de cualquier producto o actividad realizada en el espacio natural (cuadro 6).

Tabla 6

TARIFAS COTIDIANAS ${ }^{43}$ DE ALGUNOS PRODUCTOS OFERTADOS EN PARQUES QUÉBEC, VERANO/OTOÑO 2011

\begin{tabular}{|l|r|}
\hline \multicolumn{1}{|c|}{ Productos: alojamiento/actividad/material } & Precio en \$CAN (sin impuestos incluidos) \\
\hline Camping rústico, sin acondicionamiento & 20,25 noche \\
\hline Camping acondicionado sin servicios & 26,00 noche \\
\hline $\begin{array}{l}\text { Camping acondicionado con tiendas de campaña } \\
\text { instaladas (Huttopia) }\end{array}$ & 113,00 noche \\
\hline Cabaña de madera (2 personas) & 128,00 noche \\
\hline Cabaña de madera (8 personas) & 230,00 noche \\
\hline Yurta & 124,00 noche \\
\hline Iglú & 25,25 noche \\
\hline Refugio por persona & 22,50 noche \\
\hline Jornada de pesca, con embarcación (1 persona) & 54,45 día \\
\hline Jornada de pesca, con embarcación (2 personas) & 71,00 día \\
\hline Jornada de pesca, con embarcación (3 personas) & 87,55 día \\
\hline Canoa & 14,26 hora \\
\hline Kayak de mar doble & 19,75 hora \\
\hline Kayak de mar simple & 14,70 hora \\
\hline Bicicleta adulto & 11,85 hora \\
\hline Bicicleta niño & 7,24 hora \\
\hline
\end{tabular}

Fuente: Sépaq, 2011. Elaboración propia.

La Sépaq considera que la conservación es el otro pilar en la gestión de los parques nacionales, siendo su responsable el servicio de Parques del MDDEP. La Estrategia de Conservación (Stratégie de conservation) es un documento que presenta las orientaciones de cómo integrar los principios de estas políticas en la gestión de cada parque nacional. Dicha estrategia se sustenta en herramientas de planificación como son los planes de conservación específicos de cada parque (Plan Directeur) o el Programa de Seguimiento Integral Ecológico (PSIE, Programme de suivi de l'intégrité écologique ${ }^{44}$ ) iniciado en 2004. El PSIE vigila los cambios en el nivel de integridad ecológica ${ }^{45}$ de cada parque, a partir de una serie de indicadores de diferente naturaleza ${ }^{46}$ que son revisados regularmente con el fin de comprobar las modificaciones que se registren. Los parques siguen generalmente los mismos indicadores, que se encuentran adaptados a la realidad de cada uno.

43 Los precios de los alojamientos pueden aumentar en función de determinadas fechas claves en una misma temporada. Las cabañas, para los días 7, 8 y 9 de octubre elevan su precio a $189 \$$ la noche.

44 http://www.sepaq.com/dotAsset/26261.pdf (consultado en julio de 2011).

http://www.sepaq.com/dotAsset/3049951.pdf (consultado en julio de 2011).

45 Nivel de impacto humano en el territorio (creación de senderos, edificios, aparcamientos, carreteras, presencia de insectos exógenos transportados por el hombre...)

46 Los parques nacionales no siguen necesariamente todos los indicadores. http://www.sepaq.com/dotAsset/19004.pdf (consultado en julio de 2011). 
En definitiva, el PSIE es un sistema de detección precoz de problemas y debiera permitir reaccionar eficazmente, frente a situaciones de riesgo. Cada 5 años se realiza un balance de cada parque, lo que permite conocer el estado global de la integridad ecológica de la red de parques nacionales de Quebec.

Desde el MDDEP se entiende que toda estrategia de conservación debe contar con programas de investigación. Aparte de las que efectúa el personal de la Sépaq, sólo en 2007, unos 215 investigadores de diversas universidades y centros trabajaron en algún parque nacional de la Red. Los estudios realizados pueden y deben contribuir a una mejor gestión y conservación de los parques. De hecho, y a modo de ejemplo, el parque nacional de Hautes Gorges de la rivière Malbaie cambió radicalmente uno de sus senderos para favorecer la observación de fenómenos geológicos particulares que constituyen su razón de ser constituyen su razón de ser; el inventario de flora emprendido en el parque nacional del Mont Mégantic descubrió la presencia de una planta particular, la gentiane amarelle, nunca antes catalogada en el sur de Quebec. El equipo de conservación del parque decidió tomar medidas para minimizar el impacto de las actividades humanas sobre esta planta.

A lo largo de este apartado, hemos comprobado cómo la publicación del informe del Comité de Reactivación de los Parques Quebequenses fue el revulsivo para una verdadera reordenación institucional: la Sépaq es una apuesta por la centralización. Sin embargo, aún hay abiertos viejos debates entorno a la rentabilización de los parques. A mediados de los años 1980 se crearon en Quebec parques para salvar la naturaleza cercana a espacios urbanos, de la carnívora industria inmobiliaria, nos referimos a los parques de Mont Saint Bruno e Îles de Boucherville. A finales de esa década y durante la primera mitad de los noventa se intentó rentabilizar estos parques privatizando parte de su gestión. Este hecho propició situaciones que hoy podríamos calificarlas como sorprendentes. Se permitió la construcción de un campo de golf en el parque de Îles de Boucherville. Este debate sobre desarrollo y rentabilidad, aún hoy, sigue abierto en sectores de la administración quebequense. El ejemplo más cercano de esta afirmación, lo encontramos en el 2006, al autorizar el Gobierno la construcción de un complejo inmobiliario recreativo-turístico, en el borde del parque nacional de Mont Orford, cuyo fin era rentabilizar una estación de esquí, privada, existente en el interior del parque, antes de que éste se creara. En la actualidad, la polémica y el proyecto siguen haciendo correr ríos de tinta.

La visión utilitaria de los parques continúa presente en algunos sectores de la sociedad; para otros, no debiera planear en el horizonte de los nuevos espacios protegidos, pues no casa con el actual concepto de desarrollo sostenible. Privilegiar esa percepción, con el fin de crear una actividad económica consumiendo sus recursos naturales sin un plan de desarrollo sostenible coherente, presenta graves riesgos. Cada vez es más asumido el discurso que entiende como fundamental no reducir el poder de atracción de los espacios protegidos, pues éstos diversifican la economía regional con la aparición del turismo. Ya hay directores de parques quebequenses que aseveran que el desarrollo sostenible de este tipo de espacios públicos y sin asentamientos humanos, debe fijarse en el exterior del mismo; en su interior, es la gestión sostenible de los recursos naturales la que debe ser aplicada para la puesta en valor del territorio protegido con fines educativos y recreativos de bajo impacto. El medio natural no hay que desarrollarlo, se conserva valorizándolo, lo que es muy diferente. Como decía Guy Bussière ${ }^{47}$ ya en 1990: el desarrollo sostenible no implica el desarrollo de cada kilómetro cuadrado del planeta ${ }^{48}$.

47 Responsable de la comisión de de espacios protegidos de Natura Quebec y antiguo director de parque en: Huber, J (2010): «Les parcs et le développement durable», FrancVert, le webzine environnemental, vol 6, num. 3.

48 Bussières, Guy (1990) : Loisir et SociétélSociety and Leisure, volumen 13, número 2, pp.359-377, Presse de l'Université du Québec. 


\section{Importancia económica de las actividades recreativas ligadas a la naturaleza: el caso de Capital Nacional}

Capital Nacional es una región administrativa de Québec que cubre ${ }^{49} 19.286 \mathrm{~km}^{2}$. Según cifras oficiales de 2010, estaban censadas 693.859 personas - el 8,8\% de toda la población de la provincia de Quebec-. La densidad de población se eleva a 36 hab. $/ \mathrm{km}^{2}$. En ella se encuentra la capital de la provincia de Québec, la cual posee 511.789 habitantes, es decir, el $73,8 \%$ de toda provincia administrativa. Otro dato de interés es que Capital Nacional está constituida por siete municipalidades regionales de condado (MRC ${ }^{50}$, municipalités régionales de comté): Québec, Portneuf, l'Île-d'Orléans, Jacques-Cartier, Côte-de-Beaupré, Charlevoix y Charlevoix Est (mapa 3). Éstas forman dos importantes regiones turísticas ${ }^{51}$. De un lado, la región turística de Quebec $\left(13.286 \mathrm{~km}^{2}\right)$, compuesta por los municipios de Quebec, Portneuf, l'Île-d'Orléans y Jacques-Cartier, donde vive la mayor parte de la población provincial. De otro, Côte-de-Beaupré, Charlevoix y Charlevoix Est forman la región turística de Charlevoix de unos $6.000 \mathrm{~km}^{2}$ aproximadamente; con algo más de 20.000 personas censadas.

\section{Mapa 3 \\ MCR DE CAPITAL NACIONAL (QUEBEC, CANADÁ)}

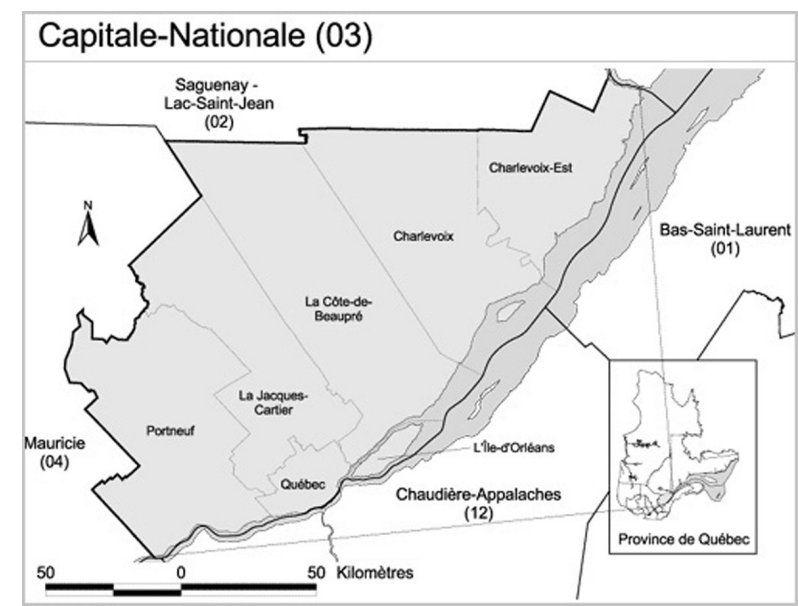

Fuente: MAPAQ [http://www.mapaq.gouv.qc.ca/fr/Regions/capitalenationale/Pages/profil.aspx]

Los espacios naturales de Capital Nacional representan una baza innegable para su desarrollo turístico. La región ofrece una amplia gama de actividades recreativas para los amantes de la naturaleza, fruto de sus tres parques nacionales (los cuales trataremos a continuación), su reserva nacional de fauna (Cap-Tourmente), sus dos reservas faunísticas (Portneuf y

49 Para tener un referente, la provincia de Ciudad Real se extiende por $19.813 \mathrm{~km}^{2}$.

50 Las MRC fueron creadas en 1979 por el gobierno de Quebec en virtud de la Ley de ordenación y territorio. Su objetivo es el de asegurar un desarrollo armonioso y coherente; son responsables de las competencias de ordenación del territorio, desarrollo económico, gestión de aguas, seguridad pública, servicio de bomberos y residuos. Suelen estar constituidas por los alcaldes de las localidades que forman la comarca y un representante del municipio donde está la sede.

51 Un total de 21 regiones turísticas se distinguen en la provincia de Québec. 
Laurentides), sus cinco ZECS ${ }^{52}$ (Buteux-Bas-Saguenay, Riviere-Blanche, Lac-au-sable, Batiscan-Neilson y Martres), sus veintitrés cotos de caza, su masa forestal de aprendizaje e investigación de la Universidad de Laval (Montmorency), su estación forestal (Duchesnay) y sus cinco centros de esquí alpino (Le Massif, Le Relais, Stoneham, St. Raymond, Mont Grand Fonds y Mont Sainte-Anne). A estos espacios hay que sumarle los más de $1.000 \mathrm{~km}$. de senderos, los $1.000 \mathrm{~km}$. de riveras de lagos y ríos navegables en canoa, los $1.200 \mathrm{~km}$. de pistas de esquí de fondo, los $400 \mathrm{~km}$. de carriles para bicicletas de montaña, los $575 \mathrm{~km}$. de senderos para quads y los $2.000 \mathrm{~km}$. de senderos para motos de nieve.

Las actividades recreativas juegan un papel destacado en la economía de Capital Nacional. Máxime si consideramos los ingresos ligados a los periodos de descanso. Se estima que sólo en la región hay 12.600 cabañas de madera, de las cuales, 350 son ofertadas por la Sépaq, y 5.500 plazas de camping. La pesca genera ingresos del orden de los 110.000 \$CAN. La caza cuenta en la región con más de 30.000 adeptos. Si sólo contabilizamos las actividades ligadas a la fauna y las actividades recreativas de los veraneantes, según las autoridades locales, se generan algo más de 22.258.000 \$CAN.

\subsection{Conservación y desarrollo en los parques nacionales de capital nacional}

En relación a la conservación de la naturaleza, entre 2002 y 2009, Capital Nacional ha pasado de tener el $8,92 \%$ de su territorio bajo alguna figura de protección al 10,83\%. En este período siempre ha registrado datos superiores a la media de la provincia de Quebec $(2,88 \%$ en 2002 y $8,13 \%$ en 2009). En relación a la figura de parque nacional, son tres los que se sitúan enteramente en la región: Jacques-Cartier (PNJC), Grands Jardins (PNGJ) y Hautes Gorges de la Rivière Malbaie (PNHG); además de una pequeña parte del parque nacional de Fjord du Saguenay (mapa 4). Si sólo tomamos como referencia los tres primeros, atendemos que Capital Nacional disfruta de 1.205,3 $\mathrm{km}^{2}$ de parques nacionales, o lo que es lo mismo, el 6,25\% de todo su territorio, muy por encima de la media quebequense que es del 0,63\%. La extensión de los mismos, varía entre los 670,6 km² de PNJC y los $224,70 \mathrm{~km}^{2}$ de PNHG; la superficie media es de 401,76 km², por lo tanto, por encima de la media real de la provincia de Quebec, 359,26 km² (tabla 7).

Es imposible comprender estos datos sin remontarnos al antiguo y desaparecido parque nacional de las Laurentides, creado en 1895 en tierras de la Corona. Se extendía en una superficie de $6.552 \mathrm{~km}^{2}$ (en él se encontraban lo que hoy son los parques nacionales de PNJC y PNGJ y parte de la reserva faunística de las Laurentides que en la actualidad abarca $8.760 \mathrm{~km}^{2}$ ). Fue el segundo parque en ser declarado por el Gobierno, tras el de Montagne Tremblante, creado un año antes y contaba con $60 \mathrm{~km}^{2}$. La constitución de estos dos parques quebequenses es consecuencia de una corriente conservacionista norteamericana aparecida a finales del siglo XIX. Ésta preconizaba la creación de espacios protegidos fundamentados en la belleza natural y su potencial recreativo y turístico. En consecuencia, la explotación de los recursos naturales de los parques nacionales estaba prohibida. Sin embargo, en Quebec, los propósitos fueron otros. La creación del parque de la Montagne Tremblante al igual que

52 Denominadas «zonas de explotación controlada» se constituyeron en 1978 para sustituir a los clubs privados. La gestión de estas zonas está confiada a organismos sin ánimo de lucro. Son gestionados por administradores elegidos por los miembros de cada una de las ZECS. Su objeto es gestionar la fauna de estos territorios mediante una explotación que vele por la conservación. En la provincia de Quebec existen unas 63 ZECS de caza, pesca y otras actividades recreativas al aire libre y se extienden en una superficie que ronda los $50.000 \mathrm{Km}^{2}$. Los cuatro objetivos de las ZECS son: conservación de la fauna, acceso a los recursos faunísticos, participación vecinal y autofinanciación. En 2010 las ZECS contaron con 40.000 abonados y más de 250.000 usuarios.

Más información en: http://www.zecquebec.com/index.jsp (consultado en julio de 2011). 


\section{PARQUES NACIONALES DE CAPITAL NACIONAL (QUEBEC, CANADÁ)}

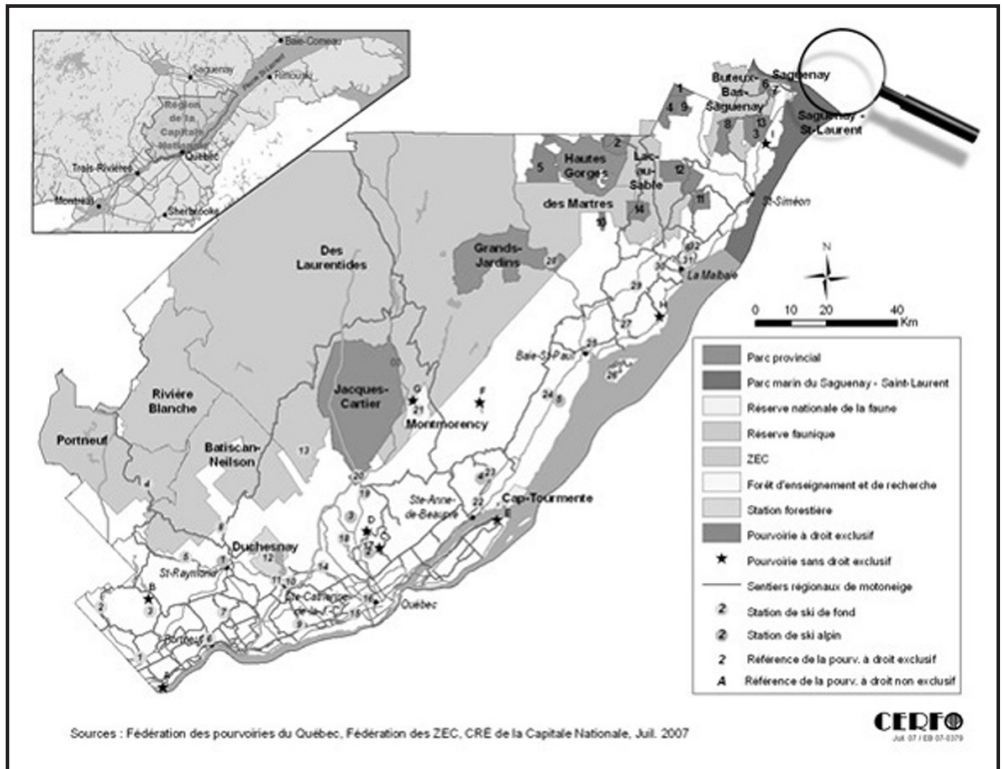

Fuente: Fédération de pourvoiries du Québec. Fédérations des ZEC, CRE de la Capitale-Nationale, 2007.

el de las Laurentides, territorios reconocidos por su potencial forestal y faunístico, si bien tuvo una voluntad teórica de protección de bosques, cursos de agua y fauna, lo cierto es que dejó abierta las puertas a la explotación de los recursos naturales. Seis meses después de la constitución del parque de las Laurentides, el gobierno concedió una parte de su territorio a la explotación forestal; en 1905, el 93\% de su superficie ya había sido destinada a este fin. Habría que esperar al año 1977 para que las reglas de la conservación dieran un giro radical, al aprobarse la Ley de Parques, resultado de los acontecimientos producidos en lo que hoy es el parque nacional de PNJC y que explicaremos a continuación.

PNJC fue uno de los primeros parques en integrar la antigua red de parques provinciales de Quebec. Su creación puede considerarse como un triunfo social. En 1972 salió a la luz pública el proyecto Champigny, que consistía en la construcción de una central hidroeléctrica en pleno corazón del valle del río Jacques Cartier (situado, como expusimos, en el antiguo parque de las Laurentides) por parte de la empresa pública Hydro-Québec. La realización del proyecto hubiese supuesto la inmediata desaparición del valle. Una centena de universitarios y vecinos del municipio Stoneham-et-Tewkesbury, consiguieron concienciar al resto de la población local del atentado natural que suponía tal proyecto. Como una bola de nieve, la presión social y mediática irían en aumento hasta que en 1975, el gobierno de Quebec lo abandonara definitivamente ${ }^{53}$. Las repercusiones de las movilizaciones y el pujante debate medioambiental deben considerarse como punto de partida para la aprobación, sólo dos años después, de la Ley de parques, base de la actual

53 Hasta 1973 el Gobierno de Quebec era de corte liberal en 1976 sube al poder el partido nacionalista Pari Québécois de René Lévesque, a quién se debe la creación de las MRC y la Ley de Protección del Medio Agrícola. 
red de Parques Quebec. Hoy, el PNJC, situado en la región turística de Quebec, es el más extenso de todos los parques nacionales de Capital Nacional. Tiene como fin, asegurar la conservación y puesta en valor de una muestra del macizo de las Laurentides, al norte de Quebec, y el excepcional valle del río Jacques Cartier.

Figura 1

VALLE DEL RÍO JACQUES CARTIER EN EL PNJC (2011)

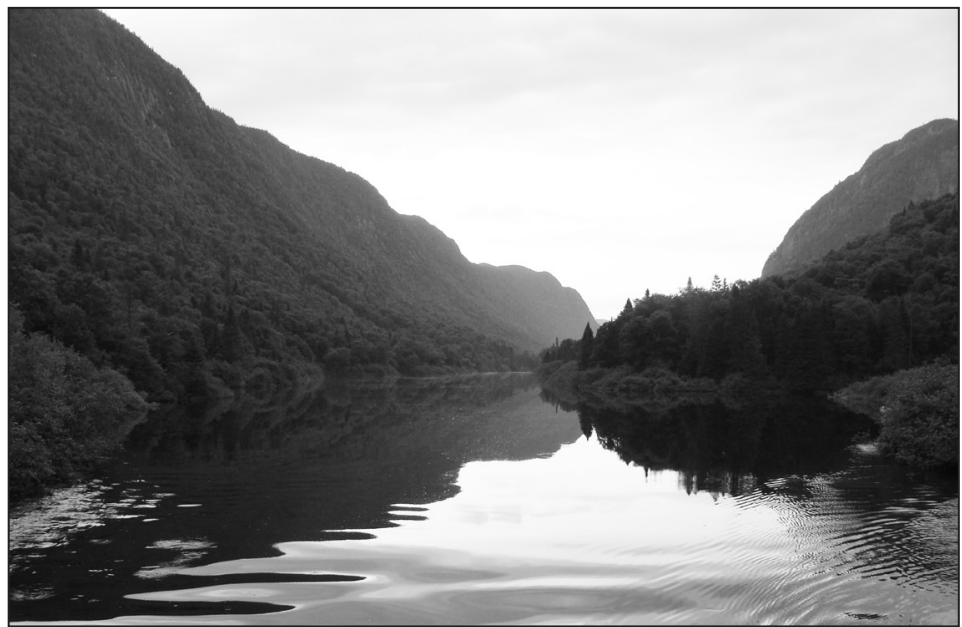

Fotografía del autor.

Figura 2

DETALLE DE PANELES INFORMATIVOS DEL PNGJ (2011)

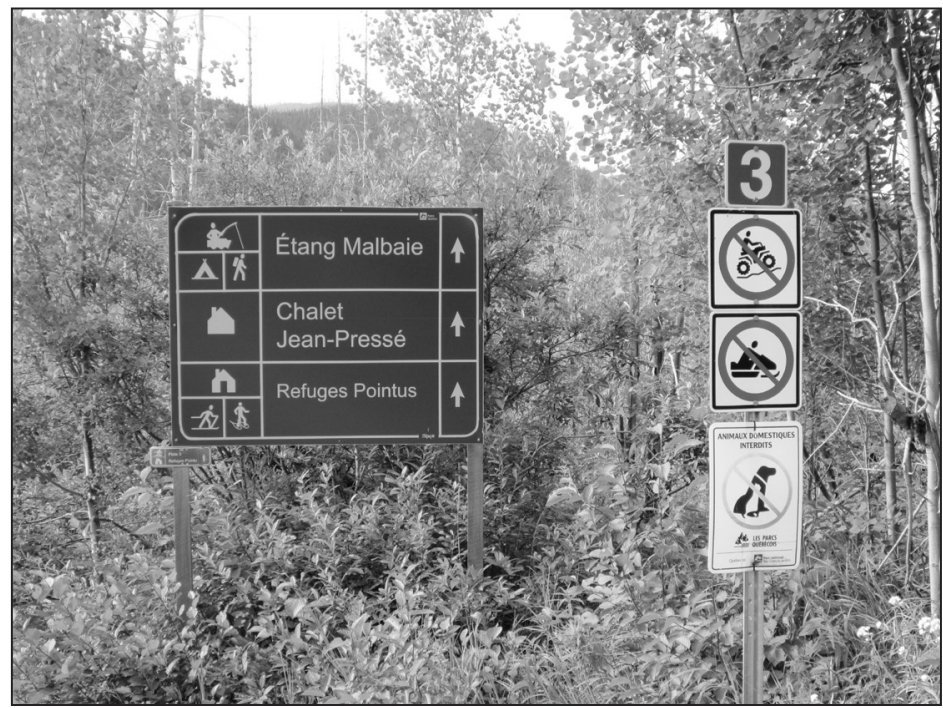

Fotografía del autor. 
Otro de los parques nacionales más antiguos es el de PNGJ, creado también en 1981 e igualmente integrante del antiguo parque de las Laurentides. PNGJ asegura la protección de un excepcional paisaje vegetal de taiga (más habitual de espacios superiores al paralelo 52, bahía James, pero presente en el parque debido a las rigurosísimas condiciones climáticas vinculadas a unas alturas que llegan en ocasiones a los $1.100 \mathrm{msnm}$ ) y la preservación del caribú (Rangifer tarandus caribou), reintroducido en 1969, una vez consumada su desaparición en la región allá por el año 1928. Hoy, alrededor de 80 caribús rondan el parque en épocas señaladas. Cabe mencionar que desde 1988, PNGJ es un espacio central de la reserva mundial de la biosfera de Charlevoix, patrimonio de conservación de la biodiversidad por la UNESCO

En último lugar, hemos dejado al más pequeño y reciente ${ }^{54}$ de los parques de Capital Nacional, nos referimos al de PNHG. Excepcionales son sus profundos valles y paredes, las más altas al este de las Rocosas y esenciales para la existencia de una cantidad considerable de cascadas que llegan a superar los $100 \mathrm{~m}$. La belleza de sus paisajes y el particular recorrido del río Malbaie crean un escenario natural propicio para manadas de caribús y martas americanas (Martes americana). En suma PNHG es un lugar excepcional desde un punto de vista geomorfológico y ecológico. Lo que le valió para convertirse en una de las áreas centrales de la reserva de la biosfera de Charlevoix junto al ya mencionado PNGJ. En consecuencia, dos de los parques nacionales de Capital Nacional tienen un reconocimiento internacional, los situados en la región turística de Charlevoix. Entre tanto, la región turística de Quebec presenta sólo un parque nacional, el de PNJC, el cual dispone de una extensión superior a la suma de la superficie de PNGJ y PNHG.

\section{Figura 3}

ACTIVIDADES RECREATIVAS EN EL RÍO MALBAIE DENTRO DEL PNHG (2011)

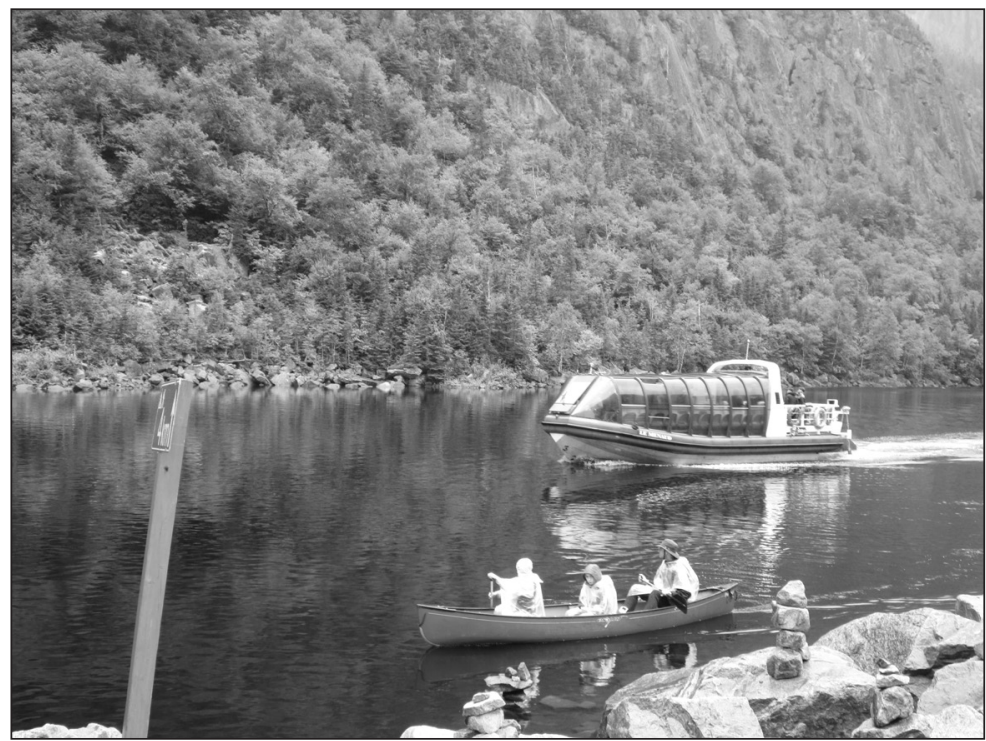

Fotografía del autor.

54 Con anterioridad había sido parque regional. 
Tabla 7

CARACTERÍSTICAS DE LOS PARQUES NACIONALES DE LA PROVINCIA ADMINISTRATIVA DE CAPITAL NACIONAL (QUEBEC)

\begin{tabular}{|c|c|c|c|}
\hline Características del parque & $\begin{array}{l}\text { Jacques Cartier } \\
\text { (PNJC) }\end{array}$ & $\begin{array}{l}\text { Grands Jardins } \\
\text { (PNGJ) }\end{array}$ & $\begin{array}{c}\text { Hautes Gorges de la rivière } \\
\text { Malbaie (PNHG) }\end{array}$ \\
\hline Año de creación & 1981 & 1981 & 2000 \\
\hline Coordenadas geográficas & $\begin{array}{l}71^{\circ} 19^{\prime} 60^{\prime \prime} \mathrm{W} \\
47^{\circ} 18^{\prime} 00^{\prime \prime} \mathrm{N}\end{array}$ & $\begin{array}{l}70^{\circ} 49^{\prime} 60^{\prime \prime} \mathrm{W} \\
48^{\circ} 65^{\prime} 60^{\prime \prime} \mathrm{N}\end{array}$ & $\begin{array}{l}70^{\circ} 28^{\prime} 00^{\prime \prime} \mathrm{W} \\
47^{\circ} 55^{\prime} 00^{\prime \prime} \mathrm{N}\end{array}$ \\
\hline Provincia natural & (D) & (D) & (D) \\
\hline Provincia administrativa & (3) & (3) & (3) \\
\hline Altura mínima/máxima (msnm) & $250 / 809$ & $350 / 1.100$ & $200 / 1.041$ \\
\hline Superficie total $\left(\mathrm{km}^{2}\right)$ & 670,6 & 310 & 224,70 \\
\hline Zona de preservación $\left(\mathrm{km}^{2}\right)$ & $279(42 \%$ total $)$ & $88(28 \%$ total $)$ & $162,43(72 \%)$ \\
\hline Número de visitas anuales ${ }^{55}$ & 120.000 & 70.000 & 90.000 \\
\hline Número de proyectos científicos (2008-2011) & $(* 56)$ & 19 & 3 \\
\hline Red de senderos a pie $e^{57}(\mathrm{~km})$. & 104,7 & 34 & 53,6 \\
\hline Red de carriles bici ${ }^{58}(\mathrm{~km})$. & 42 & 0 & 48 \\
\hline $\begin{array}{l}\text { Red de pistas de esquí de fondo y raquetas de } \\
\text { nieve }(\mathrm{km} \text {.) }\end{array}$ & $110,1\left(63,9 / 57,4^{58}\right)$ & $62(48 / 54)$ & 0 \\
\hline Red de carreteras asfaltadas abiertas al público & 12 & 0 & 8 \\
\hline $\begin{array}{l}\text { Número de emplazamientos de camping } \\
\text { (acondicionados sin servicios y rústicos) }\end{array}$ & $121(79 / 42)$ & $83(55 / 28)$ & $132(107 / 25)$ \\
\hline Número de emplazamientos de tiendas Huttopia & 14 & 11 & 19 \\
\hline $\begin{array}{l}\text { Número de refugios y/o cabañas de madera } \\
\text { (capacidad en personas) }\end{array}$ & $0 / 9(82)$ & $2 / 16(102)$ & $0 / 0(0)$ \\
\hline Atracción principal & $\begin{array}{l}\text { Actividades deportivas en } \\
\text { el río Jacques Cartier }\end{array}$ & $\begin{array}{l}\text { Pesca; sendero: «le mont-du- } \\
\text { lac-des-cygnes» }\end{array}$ & $\begin{array}{l}\text { Actividades deportivas y } \\
\text { recreativas en el río Malbaie; } \\
\text { sendero: «L'Acropole-des- } \\
\text { Draveurs» }\end{array}$ \\
\hline Actividades económicas periféricas al parque & $\begin{array}{l}\text { Actividad forestal, caza y } \\
\text { pesca }\end{array}$ & $\begin{array}{l}\text { Actividad forestal, caza, } \\
\text { pesca, ganadería y agricultura }\end{array}$ & $\begin{array}{l}\text { Actividad forestal, caza, } \\
\text { pesca, ganadería y agricultura }\end{array}$ \\
\hline Recaudación estimada (2010, en \$CAN) & 2.000 .000 & Sin datos ${ }^{59}$ & 1.700 .000 \\
\hline Presupuesto aproximado (2010, en \$CAN) & 1.990 .000 & 5.000 .000 & 3.000 .000 \\
\hline Empleados temporada alta y baja & $66 / 12$ & $40 / 7$ & $65 / 4$ \\
\hline
\end{tabular}

Fuente: Ministerio de Desarrollo Sostenible, Medio Ambiente y Parques (Gobierno de Quebec) ${ }^{61}$ y Sépaq. Elaboración propia ${ }^{62}$.

55 El parque nacional de Hautes Gorges de la rivière Malbaie sólo ofrece temporada de verano (desde mediados de marzo a mediados de octubre). Tanto Jacques Cartier como Grands-Jardins ofrecen actividades también en temporada invernal.

56 La Universidad de Laval posee colindante al PNJC la estación experimental de Forêt de Montmorency de 6.664 ha y gestionado por la Facultad de Ciencias Forestales de la UL. En 1964, este territorio fue donando por el Gobierno de Quebec bajo la figura de censo enfitéutico por un período de 99 años. Es un lugar de continua investigación.

57 Se contabilizan los kilómetros de los senderos lineales de ida y vuelta.

58 Se contabilizan los kilómetros de los carriles lineales de ida y vuelta.

59 El esquí de fondo y las raquetas de nieve comparten $11,2 \mathrm{Km}$.

60 Desde los incendios de la década de 1990 los ingresos de este parque han disminuido considerablemente en relación con los de su entorno. Se estima que sus ingresos son menores a los del PNHG.

61 http://www.mddep.gouv.qc.ca/biodiversite/aires_protegees/registre/reg-design/index.htm

(consultado en julio de 2011).

62 http://www.mddep.gouv.qc.ca/biodiversite/aires_protegees/registre/reg-design/17Parc-nationalquebec. pdf (consultado en julio de 2011). 
Si bien PNHG es el parque nacional más reciente de Capital Nacional ha sido también el más polémico de la región. Esencialmente, dos fueron los problemas que se tuvieron que solventar. El primero, la recompra de doce cabañas privadas de uso recreativo en territorio público. Éstas se construyeron gracias a un sistema de alquiler de parcelas entre la provincia de Quebec e individuos particulares, quienes tuvieron vía libre para construir sus cabañas. $\mathrm{Al}$ crearse el parque nacional, la provincia decidió terminar con estos contratos mediante indemnizaciones. El segundo obstáculo, proviene del popular uso de las motos de nieve en lo que hoy es el parque nacional; práctica totalmente prohibida en estos espacios protegidos por motivos de contaminación química y acústica.

Los parques nacionales de Capital Nacional, como el resto de los integrantes de la red Parques Quebec tienen como objeto legal: asegurar la conservación y la protección permanente del territorio, así como finalidades de carácter educativo y recreativo. A estas metas hay que sumarle otra de carácter político, la autofinanciación, claramente marcada en las directrices de los presupuestos de cada parque. Para conseguir dichos propósitos, los parques poseen dos herramientas: el plan director (plan directeur) y el plan de negocio (plan d'affaires). El primero, reagrupa la suma de los elementos que el Ministerio considera que hay que conservar y son esenciales en la condición de parque nacional. Divide el territorio en zona ambiente, de preservación y preservación extrema ${ }^{63}$ (tabla 7). El plan se acompaña de un inventario de datos relativos a los recursos naturales, arqueológicos e históricos del territorio y de la demanda regional en materia de espacios protegidos, recreativa, educativa sobre el medio natural, alojamiento, etc. El análisis de estos datos y su síntesis permiten identificar los sectores a conservar y la valorización de aquellos menos propicios para el desarrollo de actividades recreativas. El segundo de los planes, tiene como meta la elaboración de nuevos productos educativos y recreativos. Así se satisface el conocimiento y difusión de los parques nacionales, además de la diversificación de los productos ofertados para alcanzar la autofinanciación.

Los parques nacionales se financian con sus propicios recursos, por ello es que deben de tener todos los años unos presupuestos en los que se recojan los ingresos previstos. En el caso de que el cierre de cuentas sea positivo, el superávit irá directamente a una caja común que servirá para redirigir fondos, bajo la nomenclatura de «subvención de equilibrio» a los parques con déficit. En relación a los presupuestos, el único parque nacional de Capital Nacional que aporta ingresos a dicha caja común es PNJC debido a que abre sus instalaciones todo el año, ofreciendo una variada gama de productos recreativos. Es subrayable que este parque posee tomas de luz, agua y teléfono. Por el contrario, PNGJ y PNHG no dispone de luz, ni teléfono, por lo que una parte de los gastos proceden de la obtención de energía eléctrica (generadores y placas solares) y la línea de Internet vía satélite. La autofinanciación continúa siendo un verdadero desafío para PNGJ y PNHG (tabla 7).

Según los datos manejados por las direcciones de los parques nacionales, resultantes de los estudios de seguimiento de los visitantes, la franja de edad comprendida entre los $40 \mathrm{y}$ los 50 años es la que más frecuenta los parques de Capital Nacional; la media de pernoctación es de 2,1 noches. Hay que diferenciar asimismo entre el visitante de la ciudad de

63 Se identifica como zona de preservación a aquel espacio excepcional bien sea por su interés paisajístico, vegetal o faunístico o por su fragilidad (débil capacidad de carga o presencia de especies vegetales y animales amenazadas). Si bien, para su conservación se reducen las intervenciones humanas en la medida de lo posible, se acompaña de una revalorización del espacio desde un punto de vista educativo por medio de visitas reducidas; las actividades al aire libre se restringen y se limitan las instalaciones de camping que generalmente van a ser de tipo rústico, la presencia de refugios también está permitida. Se prohíbe todo acceso motorizado, salvo, excepcionalmente, con fines de servicio y/o gestión. Toda explotación faunística o forestal está prohibida. La figura de protección superior a la citada es «zona de preservación extrema», muy escasa en los parques nacionales. La «zona ambiente» es la menos restrictiva de las tres citadas. 
Quebec, el cual suele acercarse a estos espacios durante una jornada, y el que proviene de Montreal o Laval, a más de dos horas en coche de PNJC (el parque nacional más cercanos a mencionadas urbes), que acostumbra a pernoctar en los parques. Los datos que maneja el MDDEP afirman que uno de cada quince dólares generados por el sector turístico proviene de la red de parques nacionales. La búsqueda de la calidad y nuevos productos es básico para aumentar las pernoctaciones y el número de visitantes, ya sean nuevos o recurrentes.

Si bien se desea mejorar la accesibilidad a estos espacios protegidos por medio del transporte público, en la actualidad, el único medio para acercarse a los parques es el vehículo privado; ello condiciona que haya franjas de edades y grupos sociales a los que se les limitan las posibilidades de acceso, con lo cual, los fines educativos y de difusión, se limitan. Otro punto que se desea potenciar es la mejora de los conocimientos de los recursos naturales del territorio para su mejor conservación y puesta en valor. En octubre de 2009, la Sépaq organizó el coloquio sobre la investigación científica en la red de parques nacionales titulado «La connaissance au service de la conservation ${ }^{64} \gg$ destinada a la comunidad científica, profesionales y gestores, interesados en la investigación en los parques nacionales.

La gestión siempre encuentra tensiones, unas veces nacidas por la ignorancia de las normas, en ocasiones por la desconsideración hacia las figuras de protección de la naturaleza y otras, por servidumbres históricas que chocan con la normativa vigente. Los parques nacionales de Capital Nacional no están exentos de dichas tensiones, valgan como ejemplo, los siguientes casos. Comencemos por el proyecto de mejora de la carretera 175 (QuebecSaguenay, route 175), frontera oriental del PNJC, que fue presentado en 2003 por el Ministerio de Transportes de Quebec. El estudio recogía un aumento de la anchura de la calzada de $32 \mathrm{~m}$ a $90 \mathrm{~m}$ (de dos a cuatro carriles), ocupando parte de los dominios periféricos de la zona este del PNJC. A pesar de estar abierto el período de información y haberse presentado diversas alegaciones en la Audiencia pública ambiental de Quebec (BAPE, Bureau d'audiences publique sur l'environnement du Québec $)^{65}$, las obras se iniciaron, produciéndose una corta de árboles y el movimiento de tierras. Sólo una rápida actuación de la directora del PNJC consiguió paralizar las obras. Tras diversos hechos administrativos y judiciales, el Ministerio de Transporte tuvo que reparar los daños medioambientales producidos en la zona e indemnizar al parque con 300.000 \$CAN. En el PNGJ los problemas, aparte de los desafíos de gestión producidos por los incendios de los años 1990, proceden de otra carretera, la 381 (Baie Saint Paul-La Baie, route 381) límite este del parque, muy utilizada por los usuarios del mismo para acceder a la zona del estanque Malbaie, pero también, por el transporte pesado de la corta de madera de la reserva faunística de las Laurentides. Tanto en la carretera 175 como en la 381, los atropellos de animales salvajes son continuos; incluso, alguno se ha saldado con el fallecimiento de personas. Por último, existen tensiones con el derecho de caza que asiste a las poblaciones autóctonas de Canadá desde los primitivos tratados firmados con la Corona británica y cuya práctica, se ha convertido en servidumbre en los parques nacionales.

\section{Reflexión final}

Conservar, difundir y gestionar los recursos económicos, fruto de la utilización de estos espacios naturales, son el fundamento de una red de parques nacionales que durante la primera década del siglo XXI ha sabido adaptarse a los nuevos desafíos. Los parques nacionales de Quebec y por ende de Capital Nacional, son territorios privilegiados para la

64 www.sepaq.com/pq/colloque/ (consultado en julio de 2011).

65 La Unión Quebequense de la Conservación de la Naturaleza (UQCN, Union québécoise pour la conservation de la nature) presentó un amplio informe sobre la penetración de la calzada en el PNJC. 
práctica del ecoturismo, creadores de empleo y necesarios en la protección de territorios representativos. Los parques constituyen un ejemplo de desarrollo sostenible, donde las actuaciones en materia de protección y educación se transforman en repercusiones económicas significativas para las poblaciones locales de las áreas de influencia.

\section{Bibliografía}

Araque JimÉnez, E. (2001): «Espacios protegidos y desarrollo turístico. El ejemplo de los Parques Naturales de la provincia de Jaén», en Cantarero Quesada, J. M. (Coord.): Planificación y gestión del turismo en el medio rural, Centro de Turismo Interior de Andalucía, Jaén, pp.143-179.

Araque JimÉnEZ, E.; Crespo Guerrero, J.M. (2010): «Tourisme, territoire et environnement sur la côte méditerranéenne du Maroc», en Cahiers de la Méditerranéen, $\mathrm{n}^{\circ}$ 81, pp. 331-348.

Araque JimÉnez, E.; Crespo Guerrero, J.M. (2010): «Conservation versus développement ? Une nouvelle situation conflictuelle dans les parcs naturels andalous», en Cahiers de Géographie, $\mathrm{n}^{\circ} 10$, pp. 113-124.

Audet, V. ; Bélanger, L. ; Doucet, L. (2004): «Un nouveau type d'aire naturel pour le Québec : le paysage humanisé», en Le naturaliste canadien, vol. 128, n 2, pp. 111-118.

BÉDARD, F.; BouALEM, K. (2004): «Développement et tourisme: une relation durable», en Téoros, $\mathrm{n}^{\circ} 23$, en línea desde el 1 de enero de 2011, consultado el 10 de agosto de 2011.

Beouchet, P; Bouhaouala (2007): «Les parcs d'activités sportives récréatives en forêt : diagnostics et perspectives durables», en Téoros, $\mathrm{n}^{\circ} 26$, en línea desde el 1 de febrero de 2011, consultado el 12 de agosto de 2011.

Bussières, Guy (1990) : Loisir et Société/Society and Leisure, vol. 13, n 2, Presse de l'Université du Québec. Quebec, 359-377 pp.

Crespo Guerrero, J.M.; Cruz Cerezo, M. (2003): «Gestión de los espacios protegidos», en Foro de Papel, n ${ }^{\circ}$ 4, pp. 101-115.

Crespo Guerrero, J.M.; Cruz Cerezo, M. (2002): «Planificación de los espacios protegidos», en Foro de Papel, no 3, pp. 123-145.

Dearden, P.; Dempsey, J (2004): «Protected areas in Canada: decade of change» en The Canadian Geographer, vol. 48, n 2, pp. 225-239.

Gagnon, C.; Gagnon, S. (2006): L'écotourisme entre l'arbre et l'écorce. De la conservation au développement viable des territoire. Presses de l'Université du Québec. Québec.

Garayo UrRuela, J. M. (2001): «Los espacios naturales protegidos: entre la conservación y el desarrollo», en Lurralde, $\mathrm{n}^{\circ}$ 24, pp. 271-293.

HérITIER, S.; LASLAz, L. (2008): Les parcs nationaux dans le monde : protection, gestion et développement durable. Carrefours. Les dossiers. Ellipses. Paris, pp. 267-288.

HÉRITIER, S.; MoumaneIx, C. (2007): «Protection et gestion dans le parcs nationaux canadiens et états-uniens» en Cahiers de Géographie du Québec, nº 51, pp. 155-176.

LAHAYE, N. (2007): «La dimension conflictuelle de la valorisation touristique d'un espace naturel protégé : le cas du Mont Orford», en Téoros, $\mathrm{n}^{\circ} 26$, en línea desde el 1 de febrero de 2011, consultado el 10 de agosto de 2011.

LAPLANTE, MARC (1996): L'expérience touristique contemporaine, fondements sociaux et culturels, Quebec, Presse de l'Université du Québec.

LEQuin, M. (2003): «Développement touristique et eco-compatibilité : le cas du parc marin du Saguenay-Saint-Laurent au Québec» en Market Managemenet, n², vol.3.pp. 51-67.

Marcotte, P; Bordeau, L. (2009): «Les parcs nationaux du Québec : une expérience touristique, l'accessibilité et les défis», en FrancVert, le webzine environnemental, vol. 6, nº 2. 
MCARThUR, R.H.; WILSON E.O. (1968): «An equilibrium theory of insular zoogeography», en Evolution, no 17 , pp. 373-387.

Ministère du Loisir, de la Chase et de la Pêche (1990) : Parc des Grands Jardins. Le plan directeur. Direction du plain air et parcs, Service des études et des politiques, Bibliothèque Nationale du Québec. Québec, 1-11 pp.

Prévost, E. (1995): «1900-1929: affirmation du Québec comme destination touristique» en Téoros, $\mathrm{n}^{\circ}$ 14, en línea desde el 5 de marzo de 2010, consultado el 12 de agosto de 2011.

Sarakinos, H; Nicholls, A.O.; Tubert, A.; Aggarwal, A.; Margules, C.R.; Sarkar, (2001): "Area prioritization for biodiversity conservation in Quebec on de basis of species distributions: a preliminary analysis», en Biodiversity and conservation, $\mathrm{n}^{\circ} 10, \mathrm{pp} .1419-1472$.

Sociétés de la faune ET Des PARCS Du QuéBeC (2004) : Parc national des Hautes-Gorgesde-la-Rivière-Malbaie. Direction de la planification des parcs, Bibliothèque Nationale du Québec. Québec. 